\title{
Cranial osteology of the Early Cretaceous turtle Pleurosternon bullockii (Paracryptodira: Pleurosternidae)
}

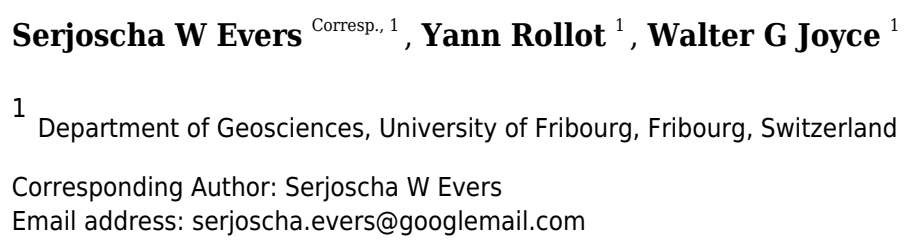

Pleurosternon bullockii is a turtle from the Early Cretaceous of Europe known from numerous postcranial remains. Only one skull has so far been referred to the species. Pleurosternon bullockii belongs to a group of turtles called pleurosternids, which is thought to include several poorly known taxa from the Late Jurassic and Early Cretaceous of Europe and North America. Pleurosternids and baenids, a group of North American turtles that lived from the Late Cretaceous to the Eocene, define a clade called Paracryptodira. Additionally, Paracryptodira likely includes compsemydids, and, potentially, helochelydrids. Character support for Paracryptodira is relatively weak, and many global phylogenetic studies fail to support paracryptodiran monophyly altogether. Proposed paracryptodiran synapomorphies are largely cranial, despite the poor characterization of pleurosternid cranial material. In addition to their questionable monophyly, the global position of paracryptodires is debated. Early studies suggest crown-turtle affinities, but most phylogenies find them as stem-turtles, irrespective of their monophyly. Here, we document the cranial osteology of Pleurosternon bullockii with the use of three-dimensional models derived from segmenting high-resolution X-ray micro-computed tomography (CT) scans. Pleurosternon bullockii has a primitive basipterygoid region of the skull, but a cryptodirelike acustico-jugular region. A surprising number of similarities with pleurodires exist, particularly in the laterally expanded external process of the pterygoid and in the posterior orbital wall. Our observations constitute an important step toward a phylogenetic reevaluation of Paracryptodira. 


\section{Cranial osteology of the Early Cretaceous turtle Pleurosternon}

\section{2 bullockii (Paracryptodira: Pleurosternidae)}

4 Serjoscha W. Evers ${ }^{1}$, Yann Rollot ${ }^{1}$ and Walter G. Joyce ${ }^{1}$

$6{ }^{1}$ Department of Geosciences, University of Fribourg, Fribourg, Switzerland

8 Corresponding Author:

$9 \quad$ Serjoscha W. Evers ${ }^{1}$

10 Chemin de Musée 6, 1700 Fribourg, Switzerland

11 Email address: serjoscha.evers@unifr.ch

\section{ABSTRACT}

Pleurosternon bullockii is a turtle from the Early Cretaceous of Europe known from numerous postcranial remains. Only one skull has so far been referred to the species. Pleurosternon bullockii belongs to a group of turtles called pleurosternids, which is thought to include several

17 poorly known taxa from the Late Jurassic and Early Cretaceous of Europe and North America.

18 Pleurosternids and baenids, a group of North American turtles that lived from the Late

19 Cretaceous to the Eocene, define a clade called Paracryptodira. Additionally, Paracryptodira

20 likely includes compsemydids, and, potentially, helochelydrids. Character support for

21 Paracryptodira is relatively weak, and many global phylogenetic studies fail to support

22 paracryptodiran monophyly altogether. Proposed paracryptodiran synapomorphies are largely 23 cranial, despite the poor characterization of pleurosternid cranial material. In addition to their 
24 questionable monophyly, the global position of paracryptodires is debated. Early studies suggest 25 crown-turtle affinities, but most phylogenies find them as stem-turtles, irrespective of their

26 monophyly. Here, we document the cranial osteology of Pleurosternon bullockii with the use of

27 three-dimensional models derived from segmenting high-resolution X-ray micro-computed 28 tomography (CT) scans. Pleurosternon bullockii has a primitive basipterygoid region of the 29 skull, but a cryptodire-like acustico-jugular region. A surprising number of similarities with 30 pleurodires exist, particularly in the laterally expanded external process of the pterygoid and in 31 the posterior orbital wall. Our observations constitute an important step toward a phylogenetic 32 re-evaluation of Paracryptodira.

34 Key words: Testudines, Paracryptodira, Pleurosternidae, Baenidae, systematics, turtles 35

\section{INTRODUCTION}

37 Paracryptodires are often referred to as 'one of the three primary clades of (crown) turtles' (e.g. Joyce, 2017). This assessment is primarily based on unresolved phylogenetic positions between Pleurodira, Cryptodira, and Paracryptodira among early global phylogenetic studies (e.g. Joyce, 2007). However, most recent phylogenetic analyses recover paracryptodires as stem-turtles, just outside of the turtle crown (e.g. Sterli, 2010; Rabi et al., 2014; Cadena \& Parham, 2015; Zhou \& Rabi, 2015; Joyce et al., 2016; Evers \& Benson, 2019). Paracryptodires were originally defined as a group of turtles that includes baenids, pleurosternids (including 'Glyptopsidae' of Gaffney, 1972), Compsemys victa, and Kallokibotion bajazidi (Gaffney, 1975a). Although only one formal phylogenetic analysis has since found these exact turtles in a monophyletic group (a Lyson \& Joyce, 2011 analysis of the matrix of Gaffney et al., 2007), a sister relationship of 
47 baenids with pleurosternids has been found frequently (e.g., Gaffney et al., 2007; Joyce, 2007;

48 Lyson \& Joyce, 2011; Pérez-García, Royo-Torres \& Cobos, 2015; Joyce et al, 2016; Joyce \&

49 Rollot, in press). As a consequence, most authors associate the term 'Paracryptodira' with a

50 clade that either exclusively includes baenids and pleurosternids (e.g. Joyce, 2007), or a clade

51 that minimally includes these clades, variously joined by compsemydids, helochelydrids, or

52 indeterminate paracryptodiran taxa (Lyson \& Joyce, 2011). Lyson \& Joyce (2011) formalized

53 this notion of Paracryptodira by coining a stem-based phylogenetic definition that includes

54 Pleurosternon bullockii and Baena arenosa as its internal specifiers. Character support for

55 Paracryptodira is relatively weak. The main osteological feature that has historically been used to

56 unite paracryptodires is a far anteriorly positioned foramen for the entry of the internal carotid

57 artery (foramen posterius canalis carotici interni; Rabi et al., 2013) formed midway along the

58 parabasisphenoid-pterygoid suture (Gaffney, 1975a). This feature persists to be cited as

59 diagnostic for paracryptodires (see review of Joyce \& Anquetin, 2019), although the foramen has

60 repeatedly been interpreted to be absent altogether in at least some paracryptodires (Sterli et al.,

61 2010; Rabi et al., 2013; Anquetin \& André, 2020). Additionally, many of the other originally

62 proposed characters in support of the group are symplesiomorphically present in Testudinata

63 (e.g. presence of nasal, reduced prefrontal exposure on skull roof, presence of mesoplastra,

64 presence of paired gular scutes; Gaffney, 1975a). Some proposed synapomorphies, such as the

65 reduction of the palatine artery (Gaffney, 1975a) or a reduced fenestra perilymphatica (Joyce,

66 2007), are, similar to the aforementioned position of the foramen posterius canalis carotici interni

67 midway along the parabasisphenoid-pterygoid suture (Gaffney, 1975a; Joyce \& Anquetin, 2019),

68 not universally present in paracryptodires (e.g. Anquetin \& André, 2020; this study) and should

69 thus be re-evaluated on a broader scale. Ambiguity in character support of Paracryptodira is also 
70 implicit from many global phylogenetic studies that fail to retrieve the constituent taxa as

71 monophyletic altogether (Sterli, 2010; Anquetin, 2012; Sterli, Pol \& Laurin, 2013; Cadena \&

72 Parham, 2015; Rabi et al., 2014; Zhou \& Rabi, 2015; Joyce et al., 2016; Evers \& Benson, 2019).

73 Although most frequently cited paracryptodiran synapomorphies are cranial characters, non-

74 baenid paracryptodiran skulls are poorly known (Joyce \& Anquetin, 2019). Five taxa have

75 relatively complete skulls, including the compsemydid Compsemys victa (Lyson \& Joyce, 2011),

76 the indeterminate paracryptodire Uluops uluops (Carpenter \& Bakker, 1990), and the

77 pleurosternids Glyptops ornatus (Gaffney, 1979a), Dorsetochelys typocardium (Evans \& Kemp,

78 1976) and Pleurosternon bullockii (Evans \& Kemp, 1975). Here, we re-examine UMZC T1041,

79 the cranium of Pleurosternon bullockii that was originally described as Mesochelys durlstonensis

80 by Evans \& Kemp (1975), based on high-resolution micro-computed tomography (CT) scanning.

81 We describe the cranium in detail and compare it to available material of other paracryptodires,

82 and, where relevant, other groups of turtles. Thorough anatomical characterizations like the one

83 presented here form the base work for phylogenetic assessments. Our description and

84 comparisons provide anatomical evidence for unique morphologies of pleurosternids, which

85 likely include at least Uluops uluops besides Pleurosternon bullockii and Glyptops ornatus.

86 Pleurosternids show a mixture of plesiomorphic and derived features, tentatively supporting their

87 inferred position as stem-taxa that are relatively close to the crown-node of turtles. We hope that

88 our descriptions lead to the coding of novel phylogenetic characters, that further scrutinize the

89 monophyly and global position of paracryptodires.

90

91 MATERIAL \& METHODS 
92 High-resolution X-ray computed tomography (CT) scans were obtained for the cranium of

93 UMZC T1041, which is the holotype of Mesochelys durlstonensis Evans \& Kemp, 1975. UMZC

94 T1041 was found in the Early Cretaceous (Berriasian) Purbeck Limestone Group in Durlston

95 Bay, United Kingdom (Evans \& Kemp, 1975). Gaffney \& Meylan (1988) referred the material to

96 Pleurosternon bullockii Owen, 1842, albeit without justification. Milner (2004) compared the

97 shell remains associated with the cranium of Mesochelys durlstonensis with those of

98 Pleurosternon bullockii, and presented anatomical evidence for the synonymy suggested by

99 Gaffney \& Meylan (1988). This has generally been accepted ever since (see review of Joyce \&

100 Anquetin, 2019). Scans of UMZC T1041 were obtained by Roger Benson in 2017 at the

101 Cambridge Biotomography Center, using a X-Tek H $225 \mu$ CT scanner (Nikon Metrology, Tring,

$102 \mathrm{UK}$ ). The cranium was scanned using a beam energy of $130 \mathrm{kV}$, a current of $250 \mu \mathrm{A}, 500 \mathrm{~ms}$

103 exposure time, 1 frame per 1400 projections, and no filter, resulting in a voxel size of 0.03315

$104 \mathrm{~mm}$. The resulting CT-scans were segmented in the software Mimics (v. 16.0-19.0;

105 http://biomedical.materialise.com/mimics), and 3D models were exported as .ply files. Figures of

106 digital renderings were compiled using the software Blender v. 2.71 (blender.org). CT-slice data

107 as well as the 3D models are deposited at MorphoSource (Evers, 2020).

108 We mostly compare UMZC T1041 to a selection of likely paracryptodires from the Late

109 Jurassic to Cretaceous of North America and Europe based on description published in the

110 literature, in particular Arundelemys dardeni (as described by Lipka et al., 2006), Compsemys

111 victa (as described by Lyson \& Joyce, 2011), Dorsetochelys typocardium (as described by Evans

112 \& Kemp, 1976 under the name Dorsetochelys delairi), Eubaena cephalica (as described by

113 Rollot, Lyson \& Joyce, 2018), Glyptops ornatus (as described by Gaffney, 1979a under the name

114 Glyptops plicatulus), and Uluops uluops (as described by Carpenter \& Bakker, 1990). For 
115 comparisons with Dorsetochelys typocardium, we used a 3D model of the holotype (DORCM

116 G.00023) that was made available under a CC-BY-NC-SA license by the "GB3D Type Fossils"

117 projects hosted by the British Geological Survey at www.3d-fossils.ac.uk. The descriptions of

118 Compsemys victa (based on UCM 53971) and Uluops uluops (based on UCM 49223) were

119 complemented by CT scans of these specimens. The original descriptions are cited for all

120 previously described features, but the specimen numbers are cited when novel observations

121 regarding these taxa are made based on these scans. These scans will be further discussed and

122 made public in a forthcoming paper.

123

\section{DESCRIPTION}

125 General comments. The cranium of UMZC T1041 disarticulated into several blocks of fully to 126 partially articulated bones, which were then displaced to give the skull a crushed appearance

127 (Figs. 1, 2). The 3D anatomy of individual bones is nevertheless near perfect. For instance, the 128 left pterygoid, prootic, opisthotic, quadrate, and the parabasisphenoid form a block in which 129 these bones are still mostly preserved in their original positions relative to one another. The 130 parabasisphenoid, however, is shifted medially relative to the pterygoid.

131 The skull of UMZC T1041 is relatively low dorsoventrally, relatively narrow mediolaterally,

132 but elongate anteroposteriorly (Figs. 1, 2). The orbits face more laterally than in Glyptops 133 ornatus (Gaffney, 1979a), but less so than in Compsemys victa (Lyson \& Joyce, 2011). The

134 entire skull roof and lateral side of the skull of UMZC T1041 is covered by the dense surface

135 sculpturing that is characteristic of many paracryptodires (e.g., Pérez-García, 2014; Joyce \&

136 Lyson, 2015; Joyce \& Anquetin, 2019). Although superficially the surface sculpturing of

137 paracryptodires is very similar among species, some differences can be made out. For instance, 
138 although the main textural element in both Uluops uluops (Carpenter \& Bakker, 1990; UCM

139 53971) and Pleurosternon bullockii (UMZC T1041) are small and irregular tubercles, these

140 transition into a ridge-like arrangement on the posterior margin of the parietal in UMZC T1041

141 (Fig. 2A), but not in Uluops uluops (UCM 53971). The skull emarginations of UMZC T1041 are

142 moderately developed: the cheek emargination is relatively deep, reaching about mid-orbit in

143 lateral view. The jugal and quadratojugal margins are strongly concave and the maxilla and

144 quadrate are included in the emargination (Fig. 2C-D). The same morphology is seen in Uluops

145 uluops (UCM 53971). The medial portion of the upper temporal emargination of UMZC T1041

146 is visible as a concavity developed along the posterior margin of the parietal that exposes only a

147 small part of the floor of the adductor chamber (Fig. 2A), again as in Uluops uluops (UCM

148 53971). The lateral portions of the upper temporal emargination that were likely formed by the

149 squamosal are damaged. Squamosal and supraoccipital crests are comparatively strongly

150 developed, providing elongate attachment sites for the adductor musculature.

151

152 Nasal. Only the left nasal of UMZC T1041 is preserved (Fig. 2A, C, E). However, as the left

153 nasal is in articulation with the frontal, prefrontal, and maxilla on the left side, the anterior region

154 of the skull roof can be completely reconstructed. The nasal is a triangular element that tapers

155 posteriorly and inserts into a gap between the prefrontal and frontal. The long anterior frontal

156 processes separate the paired nasals posteriorly, but anteriorly a short nasal-nasal suture can be

157 inferred, which is generally present in basal paracryptodires (Gaffney, 1972; Lyson \& Joyce,

158 2015; Joyce \& Anquetin, 2019).

159 
160 Prefrontal. Both prefrontals of UMZC T1041 are preserved (Fig. 2). The prefrontal has a small

161 skull roof exposure in UMZC T1041, and is restricted to a small area at the anterodorsal orbital

162 margin, contacting the nasal, frontal, and maxilla. Evans \& Kemp (1975) also reported a contact

163 with the vomer. The relevant part of the specimen has since been lost, but the side of the

164 descending process makes this contact highly plausible. Medially, the frontals hinder both

165 prefrontals from a mutual contact. Anterolaterally, the prefrontal has a deep vertical groove for

166 the reception of the ascending process of the maxilla, which is partially exposed on both sides

167 due to partial disarticulation. However, on the left side, the maxilla and prefrontal are articulated

168 enough to see that a small foramen orbito-nasale was laterally and dorsally framed by both

169 bones. As the vomer and palatine bones are absent, the medial margin of the foramen is

170 unknown. However, the foramen was medially probably closed by the palatine, as in Uluops

171 uluops (UCM 53971).

172

173 Frontal. Both frontals are preserved (Fig. 2). The frontal contacts the nasal, prefrontal,

174 postorbital, and parietal. The frontal is a relatively elongate, but narrow bone in UMZC T1041:

175 the anterior portion forms long and narrow processes that divide the internasal contact for half of

176 the nasal length (Fig. 2A). A process that partially separates the nasals is only slightly present in

177 Dorsetochelys typocardium (Evans \& Kemp, 1976) and Arundelemys dardeni (Lipka et al.,

178 2006), but otherwise generally absent in other paracryptodires, such as Glyptops ornatus

179 (Gaffney, 1979a), Compsemys victa (Lyson \& Joyce, 2011), or baenids (Gaffney,1972; Joyce \&

180 Lyson, 2015). The frontal contributes to the orbit in UMZC T1041 by means of a broad lateral

181 process (Fig. 2A). Ventrally, both frontals form a narrow sulcus olfactorius that extends 
182 anteriorly into the fossa nasalis (Fig. 3). The right and left crista cranii diverge posteriorly from

183 the midline and become shallower near the suture with the parietal.

184

185 Parietal. Both parietals are preserved in UMZC T1041 (Fig. 2). The parietal forms the posterior 186 and central parts of the skull roof and contacts the frontal anteriorly, the postorbital laterally, and 187 almost certainly the squamosal posterolaterally. Ventrally, the parietal contacts the 188 supraoccipital, prootic, epipterygoid, and possibly the pterygoid (Fig. 4B). The parietal forms a 189 tapering posteromedian process, which seems to have covered the supraoccipital entirely (see 190 supraoccipital). The posterior margin of the parietal is emarginated lateral to the midline, but still 191 conceals most of the otic capsule in dorsal view (Fig. 2A), as is also the case in Dorsetochelys 192 typocardium (Evans \& Kemp, 1976) and Uluops uluops (UCM 53971). The right parietal of 193 UMZC T1041 is broken posterolaterally near the squamosal, so that the contact between these

194 bones is not preserved. However, if the right squamosal were a mirror image of the one on the 195 left side, where the squamosal is missing but the parietal completely preserved, both bones would clearly have a short contact posterior to the postorbital. A squamosal-parietal contact is 197 also present in Dorsetochelys typocardium (Evans \& Kemp, 1976) and Uluops uluops (UCM 198 53971).

199 The descending process of the parietal is well-developed in UMZC T1041 (Figs. 3, 4B), 200 although the anterior margin of the process is posteriorly retracted, so that the interorbital 201 fenestra is large. Internally, the medial surface of the base of the descending process seems 202 bulged within the endocranial cavity, suggesting that Pleurosternon bullockii possibly had large 203 cerebral hemispheres. The posteroventral margin of the descending process of the parietal 204 contacts the supraoccipital posteriorly and the prootic anteriorly. At the dorsal margin of the 
205 trigeminal foramen, the parietal forms a thin posteroventral process that also frames the posterior 206 margin of the foramen, and extends to contact the pterygoid, thereby excluding the prootic from 207 contributing to the foramen (Fig. 4). This is visible on the right side of UMZC T1041, where the 208 prootic, parietal, quadrate, and partially the pterygoid and epipterygoid are preserved in 209 articulation. The same arrangement can be observed in Uluops uluops (UCM 53971) at the 210 posterior margin of the trigeminal foramen. A posteroventral process of the parietal along the 211 posterior trigeminal foramen margin has been proposed as a synapomorphy of Thalassochelydia 212 (Anquetin, Püntener \& Joyce, 2017), based on the presence of this process in Solnhofia parsonsi 213 and plesiochelyids (Anquetin, Püntener \& Billon-Bruyat, 2015). The same process has also been 214 observed in sandownids (Evers \& Joyce, 2020). The presence of this process in paracryptodires 215 as well as the aforementioned groups, all of which have recently been interpreted as stem-turtles 216 (e.g. Evers \& Benson, 2019), indicates that this could be a feature that is more widespread along 217 the crownward stem-lineage of turtles. The contacts of the parietal of UMZC T1041

218 anteroventral to the trigeminal foramen are not clearly preserved on either side of the specimen.

219 However, contacts with both the epipterygoid and pterygoid were likely present.

220 Most of the lateral contact with the postorbital is formed as a simple, planar contact without

221 further reinforcement. However, at the level of the base of the descending process, the parietal 222 expands laterally underneath the postorbital (Fig. 3). The ventral surface of this buttress is 223 hypertrophied to a mediolateral ridge between the descending process of the parietal and the 224 ventral process of the postorbital. This shallow ridge forms the posterior boundary of a shallow 225 fossa that is anteriorly bound by the medial margin of the orbital fossa, and which we identify as 226 as the roof to the sulcus palatino-pterygoideus (see postorbital). The same fossa is also present in 
227 various other turtle, though rarely reported, we note that it is particularly deep in UMZC T1041,

228 Uluops uluops (UCM 53971), and pleurodires (Gaffney, Tong, \& Meylan, 2006).

229

230 Postorbital. Both postorbitals are preserved in UMZC T1041 (Fig. 2). The postorbital contacts

231 the frontal anteromedially, the parietal posteromedially, the squamosal posteriorly, the

232 quadratojugal posteroventrally, and the jugal ventrally.

233 The postorbital of UMZC T1041 is posteriorly elongate (Fig. 2A-D) and forms the extensive

234 temporal roofing together with the parietal. However, the postorbital is excluded from the

235 posterior margin of the skull roof by a squamosal-parietal contact. The postorbital and squamosal

236 contact is located dorsal to the margin of the cavum tympani, but separated from contacting the

237 cavum or quadrate by a posterior process of the quadratojugal (Fig. 2D). The quadratojugal

238 contacts the postorbital posterior to the jugal-postorbital contact.

239 The postorbital forms the posterior margin of the orbit (Fig. 2C-D). Although the preservation

240 of UMZC T1041 leaves a bit of room for interpretation regarding the posterior orbital margin,

241 the jugal was excluded clearly from contributing to the margin of the orbit by a short ventral

242 process of the postorbital that contacted the maxilla (see jugal). Within the orbital fossa, the

243 postorbital forms an expanded ventral process that contacts the medial process of the jugal

244 ventrally (Fig. 3). Hereby, the ventral process of the postorbital nearly contacts the pterygoid,

245 and a contact with the unpreserved palatine cannot be ruled out entirely. The morphology of the

246 ventral process of the postorbital seems to be very similar in Uluops uluops (UCM 53971). In

247 this taxon, the postorbital comes close to the pterygoid and palatine, but both contacts are absent.

248 A postorbital-palatine contact is only seen in pleurodires (Gaffney, 1979b). However, the orbito-

249 temporal region of both UMZC T1041 and Uluops uluops (UCM 53971) show striking 
250 similarities to the morphology of that region in pleurodires: the medial postorbital-jugal

251 expansion forms an extended posterior wall to the orbital fossa (Fig. 3). Additionally, again as in

252 pleurodires, the passage between the temporal fossa posteriorly, and the orbital fossa anteriorly,

253 becomes strongly constricted between the ventral process of the postorbital and the descending

254 process of the parietal (Fig. 3). Furthermore, the roof of this constricted through is depressed to

255 form a shallow fossa (Fig. 3). This morphology is otherwise only found in pleurodires (e.g.

256 Gaffney, Tong \& Meylan, 2006). Thus, we use terms from the pleurodire literature to refer to

257 these respective structures; we use 'septum orbitotemporale' for the medial expanded jugal-

258 postorbital wall (Gaffney, Tong \& Meylan, 2006: fig. 25), and we use 'sulcus palatino-

259 pterygoideus' for the space between the orbital and temporal fossae (Gaffney, Tong \& Meylan,

260 2006: fig. 25), although we note that it is incipient with respect to the pleurodire morphology.

261

262 Jugal. Both jugals of UMZC T1041 are preserved (Fig. 2A-D), but the elements are

263 disarticulated slightly from their surrounding bones. Definite contacts are with the postorbital,

264 maxilla, quadratojugal, and pterygoid, and a contact with the palatine cannot be ruled out. The

265 jugal of UMZC T1041 shows typical turtle morphology with a laterally placed, vertical plate that

266 forms part of the lateral skull roof, and a medially directed process that contacts parts of the

267 palate. The jugal is removed from the ventral skull margin, as the maxilla forms a posterior

268 process that extends ventrally underneath the jugal for some distance (Fig. 2C-D). The end of

269 this maxillary process forms the beginning of the moderately deep cheek emargination, which

270 extends from the maxilla along the ventral margins of the jugal and quadratojugal. The dorsally

271 positioned jugal and step-like margin between the maxilla and jugal are also present in Uluops

272 uluops (UCM 53971), and baenids (Gaffney, 1972), but not so in Dorsetochelys typocardium 
273 (Evans \& Kemp, 1976), in which the jugal is the posterior continuation of the maxilla along the

274 labial margin of the skull.

275 It seems that the jugal was excluded from the orbital margin, as is also the case in Glyptops

276 ornatus (Gaffney, 1979a), Arundelemys dardeni (Lipka et al., 2006), and an assortment of

277 advanced baenids (Gaffney, 1972; Joyce \& Lyson, 2015; Rollot, Lyson \& Joyce, 2018) as well

278 as helochelydrids (e.g. Joyce et al., 2011; Joyce, Sterli \& Chapman, 2014): on both sides, the

279 jugal of UMZC T1041 has an anteriorly recessed surface, which is posteriorly delimited by a

280 rim. Only posteriorly to this rim does the surface of the bones show the sculpturing that covers

281 most of the external bone surfaces (Fig. 2C-D). In Uluops uluops (UCM 53971), in which the

282 jugal contributes to the orbit, the surface sculpturing of the jugal bone indeed extends to the

283 orbit. Thus, we interpret the recessed surface in UMZC T1041 to be a laterally exposed facet for

284 the overlying postorbital and maxilla. Our interpretation hereby differs markedly from that of

285 Evans \& Kemp (1975), who reconstructed a point contact of the jugal to the orbit margin.

286 Despite its likely exclusion from the orbital margin itself, the jugal of UMZC T1041 is expressed

287 medially to the orbital margin within the orbital fossa, which we call septum orbitotemporale

288 (see postorbital) (Fig. 3). Extending posteromedially from the orbital fossa, the medial process of

289 the jugal reaches the pterygoid. This section of the jugal is ventrally overlain by the maxilla. A

290 contact with the palatine might have been present in this area, but this cannot be confirmed

291 without any indication of the morphology of the palatine bone.

292

293 Quadratojugal. The quadratojugal is only preserved on the right side of UMZC T1041 (Fig.

294 2D). The quadratojugal is triradiate, as it forms a posterior process that inserts between the

295 postorbital and quadrate to contact the squamosal, extends ventrally along the anterior quadrate 
296 margin, and anteriorly towards the jugal. The quadratojugal of Pleurosternon bullockii is a

297 comparatively small bone in comparison to those of basal stem-turtles (e.g., Gaffney, 1990) or

298 baenids (e.g., Joyce and Lyson, 2015; Rollot, Lyson \& Joyce, 2018), but not as small as in

299 sichuanchelyids (Sukhanov, 2000; Joyce et al., 2016), which have quadratojugals with a greatly

300 reduced lateral exposure. The quadratojugal of UMZC T1041 is similar in size and extent to that

301 of Uluops uluops (UCM 53971). In UMZC T1041, the ventral margin of the quadratojugal

302 contributes to the moderately deep cheek emargination. Although the quadratojugal frames the

303 quadrate anteriorly, it is slightly displaced anteriorly from the margin of the cavum tympani, and

304 clearly does not closely approach the articular condyles of the quadrate.

305

306 Squamosal. Only the right squamosal of UMZC T1041 is preserved (Fig. 2). Contacts with the

307 quadratojugal, quadrate, and opisthotic can be documented, and a parietal contact is inferred. The

308 squamosal of Pleurosternon bullockii is a large element with a well-developed posterior process

309 and a deeply recessed antrum postoticum. The squamosal caps the posterior part of the quadrate,

310 and hereby forms the posterodorsal margin of the deeply developed cavum tympani, as is also

311 the case in Uluops uluops (UCM 53971), Dorsetochelys typocardium (Evans \& Kemp, 1976),

312 Compsemys victa (Lyson \& Joyce, 2011), and baenids (Joyce \& Lyson, 2015). The squamosal of

313 UMZC T1041 has a deep, incision-like facet for the opisthotic, and thus frames the paroccipital

314 process from dorsal and ventral. Whereas the anterior part of the squamosal is bulbous and

315 houses the expanded antrum postoticum, the bone narrows mediolaterally toward its posterior

316 end to form a vertically sheeted process that extends posteriorly just beyond the level of the

317 supraoccipital crest (Fig. 2A, F). 
319 Premaxilla. Both premaxillae are preserved in UMZC T1041 (Fig. 2A-E). The premaxilla

320 contacts the maxilla, but contacts with the palatine are uncertain due to incomplete preservation.

321 A contact with the vomer was originally preserved (Evans \& Kemp, 1975), but the vomer is now

322 lost (see vomer). The right premaxilla completely surrounds a clearly developed foramen

323 praepalatinum (Fig. 2B), which is only incompletely preserved on the other side. The dorsal

324 margin of the premaxilla shows that the external naris was undivided from below in

325 Pleurosternon bullockii, as described by Evans \& Kemp (1975). Within the nasal fossa, both

326 premaxillae together form a low ridge that probably serves as the insertion for the internarial

327 septum. The full labial ridge, including the premaxillae, frame a broad notch along the midline.

328 Serrations on the premaxillary labial ridge, as reported by Evans and Kemp (1975), are not

329 confirmed for UMZC T1041.

330

331 Maxilla. Both maxillae are preserved in UMZC T1041 (Fig. 2A-E). The maxilla contacts the 332 premaxilla anteriorly, the nasal and prefrontal dorsally, the jugal and postorbital posteriorly, and 333 the pterygoid posteromedially. A medial contact with the vomer was previously documented by

334 Evans \& Kemp (1975), but is not preserved anymore (see section on the vomer). A contact with

335 the palatine was likely present along the medial margin of the triturating surface. The triturating 336 surface of the maxilla is relatively narrow and lacks a medial ridge (Fig. 2B). The labial ridge is 337 ventrally deep and sharp-edged (Fig. 2B). In anterior view, the labial ridge of the maxilla and 338 premaxilla jointly frame a broad, but shallow median notch (Fig. 2E). A curved labial margin of 339 the maxilla seems common among paracryptodires, although the degree of the curvature varies.

340 UMZC T1041 is intermediate in this regard between Glyptops ornatus (Gaffney, 1979a),

341 Dorsetochelys typocardium (Evans \& Kemp, 1976), and Arundelemys dardeni (Lipka et al., 
342 2006) with a weakly curved maxilla on one side, and Uluops uluops (UCM 53971) on the other,

343 in which the curvature is very strongly pronounced. The medial margin of the incompletely

344 preserved foramen orbito-nasale of UMZC T1041 is formed by the maxilla, and the foramen

345 alveolaris superior is a comparatively large foramen positioned within that margin (best viewed

346 in the 3D models). Posterior to the ascending process, the maxilla forms the complete ventral

347 margin of the orbit (Fig. 2C-D). The margin is slightly raised to an orbital rim, medial to which

348 the maxilla forms a narrow floor of the orbital fossa. The foramen supramaxillare is small and

349 positioned immediately anterior to the jugal contact within the floor of the orbital fossa (Evans \&

350 Kemp, 1975). Posteriorly, the maxilla laterally overlaps the jugal to contact the postorbital along

351 the posterior margin of the orbit (see jugal). The maxilla also extends ventrally to the jugal with a

352 short process (Fig. 2C-D). The posterior part of the maxilla is medially expanded underneath the

353 jugal and reaches the anterior end of the external process of the pterygoid.

354

355 Vomer. Evans \& Kemp (1975) describe and illustrate a small anterior part of the vomer that was

356 articulated with the premaxillae and the prefrontals. However, this part of the vomer, alongside a

357 small posterior part of the left premaxilla is not preserved in the specimen anymore, and the

358 whereabout of the fragments that must have broken off since the description of Evans \& Kemp

359 (1975) are unclear.

360

361 Palatine. The palatines are not preserved in UMZC T1041.

362

363 Quadrate. Both quadrates of UMZC T1041 are preserved (Fig. 2B-D, F). The quadrate contacts

364 the prootic and opisthotic medially, the pterygoid anteroventrally, the epipterygoid anteriorly, the 
365 quadratojugal anterolaterally, and the squamosal posterolaterally. A point contact with the 366 supraoccipital is likely just posterior to the foramen stapedio-temporale. The lateral surface of

367 the quadrate is dominated by the deeply recessed cavity that forms most of the cavum tympani 368 (Fig. 2C-D). The quadrate forms the anterior margin of the cavum tympani, but posterolaterally 369 this structure is formed by the squamosal. The incisura columella auris is posteroventrally open, 370 as in all other paracryptodires (Joyce \& Lyson, 2015; Joyce \& Anquetin, 2019). The articular 371 process of the quadrate of UMZC T1041 does not protrude ventrally very deep and does not 372 significantly expand beyond the ventral margin of the cavum tympani. Much of the lateral 373 surface of the articular process was probably covered by the ventral ramus of the quadratojugal.

374 In ventral view, the articular surface of the process bears two weakly convex sub-facets (Fig.

375 2B), which are mediolaterally separated by a shallow sulcus (Evans \& Kemp, 1975). The medial 376 side of the articular process is buttressed by the posterior process of the pterygoid, but the 377 process does not reach the articular facet (Fig. 2B). Medially, within the cavum acustico378 jugulare, the quadrate forms together with the pterygoid and prootic the posterior foramen for the 379 canalis cavernosus. Between the prootic and quadrate, the canalis stapedio-temporalis connects 380 the cavum acustico-jugulare with the adductor chamber (Fig. 5A). The respective exiting 381 foramen, the foramen stapedio-temporale, is formed on the dorsal surface of the otic capsule at 382 the posterior limit of the contact between the quadrate and prootic (Fig. 4A). The foramen and 383 associated canal have a relatively small diameter, superficially similar to trionychians or

384 kinosternoids. However, the diameters of the stapedial and cerebral canals are about equally 385 sized in UMZC T1041, whereas the cerebral artery canal is much larger than the stapedial artery 386 canal in the aforementioned cryptodires. Immediately posterior to the foramen stapedio387 temporale of UMZC T1041, the quadrate likely has a short, superficial contact with the 
388 supraoccipital, which can also be observed in Uluops uluops (UCM 53971) and some baenids

389 like Stygiochelys estesi (Gaffney, 1972). Contacts of the quadrate with the opisthotic and

390 squamosal form the posterior aspect of the floor of the adductor chamber in UMZC T1041.

391 Anteriorly within the adductor chamber, the dorsal surface of the quadrate contributes to the

392 formation of the weakly developed processus trochlearis oticum. However, the quadrate forms

393 less of the process than the prootic. The process is developed as a shallowly concave area along

394 the quadrate-prootic contact (Fig. 4A). The processus trochlearis oticum of Uluops uluops (UCM

395 53971) is somewhat more pronounced, but otherwise similar to that of Pleurosternon bullockii.

396 The anterior quadrate surface of UMZC T1041, ventral to the processus trochlearis oticum,

397 extends anteriorly in a short epipterygoid process (Fig. 4A). This process contacts the

398 epipterygoid but is excluded from the trigeminal foramen margin by a dorsal process of the 399 pterygoid.

400

401 Epipterygoid. In UMZC T1041, we identify a small plate-like ossification ventral to the

402 trigeminal foramen as the epipterygoid and thus agree with Evans \& Kemp (1975) in the

403 identification of this element. However, the epipterygoids are difficult to segment in our CT

404 scans, due to their highly interdigitated sutures with the parietals, and fragmentation due to

405 breakage in the respective skull area. On the right side of the specimen, the epipterygoid seems

406 to be preserved close to its original position, although its dorsal margin has tipped laterally (Fig.

407 4). Here, the epipterygoid is positioned anteriorly to the epipterygoid process of the quadrate and

408 ventrally to the descending process of the parietal. If the epipterygoid were tilted back into

409 contact with the parietal, it would frame the anteroventral margin of the trigeminal foramen, its 
410 usual position (e.g., Gaffney, 1979b). The left epipterygoid, which seems to have been misplaced

411 slightly dorsally, also indicates that a contact with the prootic is likely.

412

413 Pterygoid. Both pterygoids of UMZC T1041 are preserved (Fig. 2B). The right pterygoid is

414 basically complete (Fig. 6), but has a transverse break through its center, whereas in the left

415 pterygoid, the external process is broken off but preserved. The pterygoid contacts the

416 parabasisphenoid, jugal, maxilla, parietal, epipterygoid, quadrate, prootic, opisthotic. Although

417 the palatines and the basioccipital are absent, contacts with the pterygoid seem all but certain.

418 However, as the exoccipitals are missing as well, we cannot assess if a pterygoid contact was

419 present with this bone as well. An interpterygoid contact below the rostrum basisphenoidale is

420 certainly absent (see Parabasisphenoid), but a possible midline contact anterior to the

421 parabasisphenoid cannot be ruled out, as the anterior tips of the pterygoids might be damaged.

422 The pterygoid of Pleurosternon bullockii shows a mixture of plesiomorphic and derived

423 features, as well as similarities to pleurodires and cryptodires. The general architecture of the

424 bone mimics that of most cryptodires, with a relatively long posterior process that covers large

425 parts of the cavum acustico-jugulare from ventral exposure (Figs. 2B, 5A). The posterior process

426 extends posteriorly up to the tips of the posterior parabasisphenoid processes (= anterior

427 tubercula basioccipitale; see parabasisphenoid), and certainly contacted the basioccipital, as is

428 also the case in Uluops uluops (UCM 53971). The posterior pterygoid process of UMZC T1041

429 furthermore completely covers the ventral end of the processus interfenestralis of the opisthotic

430 (Fig. 2B, 5A), as in Uluops uluops (UCM 53971) and Glyptops ornatus (Gaffney, 1979a). Thus,

431 the process is much more cryptodire-like and extensive than acknowledged in previous

432 descriptions (Evans \& Kemp, 1975), although Gaffney (1979a) corrected earlier statements of 
433 his, and also argued that in both Glyptops ornatus and UMZC T1041 the posterior process of the

434 pterygoid is indistinguishable from cryptodires. Between the articular process of the quadrate

435 and the parabasisphenoid of UMZC T1041, the posterior process of the pterygoid shows a well-

436 developed pterygoid fossa (Figs. 6A, 7C). Despite this cryptodire-like appearance, the pterygoid

437 retains a deep, pocket-like facet on its medial margin for the reception of the basipterygoid

438 processes of the parabasisphenoid (Figs. 6A, 7C). This facet is absent in the crania of all Recent

439 turtles. The medial margin of the pterygoid is laterally curved around the basipterygoid

440 articulation, which results in the formation of a window-like recess in the floor of the

441 basicranium, through which the basipterygoid process of the parabasisphenoid is partially

442 exposed, and through which the cerebral artery and the vidian nerve enter the cranium. The

443 articulation socket for the basipterygoid process within the medial surface of the pterygoid bears

444 a central foramen, which is positioned between the dorsal and ventral flanges of the

445 basipterygoid process (see Parabasisphenoid). The foramen is the entry to the canalis nervus

446 vidianus, which transmits the vidian nerve through the pterygoid towards an anterior foramen

447 that is positioned lateral to the anterior end of the crista pterygoidei (Fig. 6B). The connection of

448 these two foramina and their identification as the canalis nervus vidianus were already correctly

449 inferred by Evans \& Kemp (1975), but the foramen within the basipterygoid facet was re-

450 interpreted by Sterli et al. (2010) as the posterior entry foramen of the palatine artery. Our CT

451 scans unambiguously confirm the internal connection of the above-mentioned foramen with the

452 anterior foramen of the canalis nervus vidianus, and thus corroborate the interpretation by Evans

453 \& Kemp (1975). Gaffney (1979a) described the presence of a palatine artery canal for Glyptops

454 ornatus that extends anteriorly from within the basipterygoid articulation socket of the pterygoid,

455 but he could not find an anterior exiting foramen. Thus, it is possible that Gaffney (1979a) 
456 misinterpreted the foramen he saw, which could instead be for the vidian nerve canal, and did not

457 find an anterior palatine artery canal foramen, because it does not exist. However, this can only

458 be tested with certainty by attaining CT scans of Glyptops ornatus. For UMZC T1041, we can

459 furthermore confirm the canalis pro ramo nervi vidiani of Evans \& Kemp (1975; foramen pro

460 ramo nervi vidiani prior to revision of Rollot, Lyson \& Joyce [2018]), as a vertically oriented

461 canal that extends through the pterygoid from the floor of the canalis cavernosus to the ventral

462 pterygoid surface posterior to the parabasisphenoid articulation (Fig. 7C). The canalis pro ramo

463 nervi vidiani seems to be present in the same location in Glyptops ornatus (Gaffney, 1979a).

464 Immediately anterior to the ventral opening of the canalis pro ramo nervi vidiani of UMZC

465 T1041, a robust ridge surrounds the ventromedial margin of the pterygoid around the

466 basipterygoid facet (Evans \& Kemp, 1975). Both the ventral canalis pro ramo nervi vidiani and

467 the robust ridge are affected by the large break of the right pterygoid, but nicely preserved on the

468 left element (Fig. 7C). The ridge persists anteriorly, albeit much more shallowly, parallels the

469 parabasisphenoid suture for a short distance, and curves laterally toward the posteriorly directed

470 tip of the external pterygoid process (Fig. 6A). Evans \& Kemp (1975) interpret the ridge to be

471 the insertion for the pterygoideus musculature, and the same ridge morphology is present in

472 Glyptops ornatus (Gaffney, 1979a). In Uluops uluops (UCM 53971), the pterygoideus muscle

473 ridge is similar, but the ridge traverses the pterygoid earlier and extends to the posterior end of

474 the external process, thus defining a smaller fossa.

475 The external process of the pterygoid is extremely large in UMZC T1041 and projects

476 laterally deeply into the subtemporal fenestra (Figs. 2B, 5A-B, 6). Although many turtles,

477 including many cryptodires (e.g. chelydrids, emydids, geoemydids), have their lateral surface of

478 the external process developed to a vertical flange, this morphology seems hypertrophied in 
479 Pleurosternon bullockii. The vertical plate of the lateral surface of the external process is less 480 sheeted than in most cryptodires that have the respective flange, but is more robust, and notably 481 gently medially deflected towards its dorsal margin (Fig. 6B-C, 5A-B, 4). As such, the 482 morphology of the external process of the pterygoid of UMZC T1041 comes very close to that of 483 a pleurodiran processus trochlearis pterygoidei. Additionally, although the external process of 484 the pterygoid is anteriorly sutured to the jugular-maxillar area in many turtles, including some 485 cryptodires (chelydrids) and early stem turtles like Proganochelys quenstedtii (e.g. Gaffney, 486 1990), the deep and large facet for the articulation with the jugal (Fig. 6B-C, 4) demonstrates an 487 unusually strong structural integration of the external process into the mechanical framework of 488 the cranium, as is also seen in pleurodires. However, the lateral surface of the external process is 489 parallel to the sagittal skull plane (Fig. 2B), and the process is not laterally tilted with its 490 posterior end, as is the case in pleurodiran pterygoid trochleae. As such, the trajectory of the 491 adductor muscles, when approximated around the weak otic trochlea present on the prootic of 492 UMZC T1041, do not seem to be guided around the external process, implying functional 493 differences in the structure described for Pleursternon bullockii and the processus trochlearis 494 pterygoidei of pleurodires. As the detailed morphology of the external process is rarely described 495 in detail, we cannot exclude the possibility that this morphology is perhaps wider spread that 496 noted herein.

497 The dorsal surface of the pterygoid of UMZC T1041 is curved around the anteriorly 498 narrowing parabasisphenoid. Posteriorly, the medial part of the dorsal surface is dominated by a 499 low buttress for articulation with the prootic and parabasisphenoid, which also forms the medial 500 wall of the canalis cavernosus (Fig. 6B-C). The lateral surface of this canal is formed by the 501 crista pterygoidei. The canalis cavernosus ends anteriorly in the foramen cavernosum formed 
502 between the prootic and pterygoid. Anterior to the foramen, the canalis cavernosus continues as

503 the sulcus cavernosus and parallels the rostrum basisphenoidale of the parabasisphenoid (Fig.

504 6B-C). At the anterior end of the crista pterygoidei, there is a small exiting foramen for the

505 canalis nervus vidianus (Evans \& Kemp, 1975; Fig. 6B-C). The crista pterygoidei itself is

506 relatively low and posteriorly interrupted by a deep notch for the trigeminal foramen. In the

507 posterior margin of this foramen, the pterygoid extends dorsally to reach the parietal and thus

508 excludes the prootic from contributing to the foramen (Fig. 4B). The same dorsal process is

509 present in Uluops uluops (UCM 53971). The crista pterygoidei of UMZC T1041 is laterally

510 overlapped by the epipterygoid anterior to the trigeminal foramen (Fig. 4B).

511

512 Supraoccipital. The supraoccipital of UMZC T1041 is nearly completely preserved. It

513 ventrolaterally contacts the prootic and opisthotic and perhaps has a point contact with the

514 quadrate (Figs. 2, 4). It furthermore contacts the parietal anteroventrally and dorsally, and likely

515 contacted the exoccipital posteroventrally.

516 The supraoccipital of UMZC T1041 forms a comparatively broadly arched roof to the

517 endocranial cavity (Fig. 2F). A vertical plate extends over the entire anteroposterior length of the

518 supraoccipital, but this plate does not seem to extend posteriorly from the approximate position

519 of the foramen magnum as a supraoccipital crest (Evans \& Kemp, 1975). This crest seems

520 dorsally nearly completely covered by the parietals. The supraoccipital was likely only

521 marginally visible in the skull roof between the parietals, though much less than interpreted by

522 Evans \& Kemp (1975). This differs from the conditions in Uluops uluops (UCM 53971),

523 Glyptops ornatus (Gaffney, 1979a), and Dorsetochelys typocardium (Evans \& Kemp, 1976), in

524 which the supraoccipital crest is topped by a triangular or diamond shaped horizontal plate that 
525 forms a marginal part of the dorsal skull roof. Within the otic capsule of UMZC T1041, the

526 supraoccipital articulates with the prootic anteriorly and the opisthotic posteriorly. Between both

527 bones, the supraoccipital likely extends laterally to have a small superficial contact with the

528 quadrate, as is also the case in Uluops uluops (UCM 53971). The hiatus acusticus of UMZC

529 T1041 is a large, unossified space between the supraoccipital, prootic, parabasisphenoid, and

530 opisthotic, leaving a large opening between the inner ear cavity and the endocranial cavity.

531 Dorsally above the hiatus acusticus, the foramen aquaducti vestibuli, i.e. the canal for the

532 endolymphatic duct, is completely embedded within bone, forming a short canal from the

533 endocranial cavity into the recess of the supraoccipital that holds the common crus of the

534 labyrinth. Evans \& Kemp (1975) reported that the foramen aquaducti vestibuli is only a notch in

535 the supraoccipital margin, but as completely ossified canals exist on both sides of the

536 supraoccipital, they probably misinterpreted a small break on the left side of the element and

537 missed the small foramina. Contacts with the lost exoccipitals can be inferred from short facets

538 posterior to the articulation site for the opisthotic.

539

540 Exoccipital. The exoccipitals are not preserved in UMZC T1041.

541

542 Basioccipital. The basioccipital is not preserved in UMZC T1041.

543

544 Prootic. Both prootics of UMZC T1041 are present, but the right one is better preserved. The

545 prootic has a large exposure within the floor of the adductor chamber, forming the anteromedial

546 part of the otic capsule (Fig. 4). Its dorsal surface is transversely concave and anteroventrally

547 sloping toward the subtemporal fossa (Fig. 4A). Although this surface does not protrude 
548 anteriorly into the fossa, this morphology clearly indicates a redirecting of the jaw adductor 549 musculature. Thus, a small processus trochlearis oticum is present. A very similar morphology, 550 although more pronounced by a deeper concave flexure across the prootic, is seen in Uluops 551 uluops (UCM 53971). Anteroventrally, the prootic of UMZC T1041 forms the dorsal margin of 552 the foramen cavernosus. Slightly anterodorsally to the position of this foramen, the prootic is

553 slightly expanded transversely to form the posterior wall of the fossa epiptericum for the 554 trigeminal ganglion. However, the anteroventral margin of the prootic is excluded from the 555 trigeminal foramen itself, contra the description of Evans \& Kemp (1975; Fig. 4B).

556 Medioventrally, the prootic has a large, foot-like process that contacts the pterygoid and 557 parabasisphenoid. The medial surface of this ventral prootic process is recessed by the fossa 558 acustico-facialis, from which the facial nerve canal extends through the ventral prootic process 559 toward the canalis cavernosus, and from which the short acustic nerve canals lead into the 560 prootic part of the cavum labyrinthicum. This cavity for the labyrinth deeply excavates the 561 prootic from posterior (Fig. 5A-B). The canal for the lateral semicircular duct of the labyrinth

562 organ is already ossified within the prootic, and thus shared between prootic and opisthotic (Fig.

$5635 \mathrm{~B}, \mathrm{D})$. Ventrally, a horizontal footplate of the ventral prootic process extends posteriorly and

564 floors the anterior half of the cavum labyrinthicum (Fig. 5). This footplate contacts the opisthotic 565 across the entire transverse width of the cavum labyrinthicum, so that the fenestra ovalis is 566 completely surrounded, dorsally and ventrally, by these two bones (Fig. 5C-D). The same

567 condition is present in Uluops uluops (UCM 53971) and Glyptops ornatus (Gaffney, 1979a).

568 Laterally to the fenestra ovalis of UMZC T1041, and thus within the cavum acustico-jugulare,

569 the posteriorly exposed surface of the prootic is deeply recessed by a fossa (Fig. 5B-C), which

570 has been hypothesized to be related to the perilymphatic system of reentrant fluid-flow systems 
571 in turtle ears (e.g. Evers \& Benson, 2019; Evers et al., 2019; Foth et al., 2019), and which is also

572 present in Uluops uluops (UCM 53971). Because the fossa continues dorsolateral to the fenestra

573 ovalis onto the opisthotic, we use the term perilymphatic fossa instead of posterior prootic recess

574 as in some previous works (e.g. Evers \& Joyce, 2020). Laterally to the perilymphatic fossa, the

575 pterygoid and prootic form the posterior foramen for the canalis cavernosus. The mediodorsal

576 wall of the canalis cavernosus, formed by the prootic, is incised by a sulcus for the

577 hyomandibular nerve (Fig. 5B), which extends from the lateral foramen of the facial nerve canal

578 to the posterior foramen for the canalis cavernosus. Such a sulcus is also present in Uluops

579 uluops (UCM 53971).

580

581 Opisthotic. The opisthotics are nearly completely preserved on both sides of the cranium of

582 UMZC T1041, but while the left one remains in articulation with the adjacent prootic and

583 quadrate on the left side, the right one is ventrally displaced (Figs. 2B, F, 5C-D). The opisthotic

584 contacts the prootic anteriorly, the supraoccipital medially, the exoccipital

585 posteroventromedially, the parabasisphenoid ventrally, the quadrate and squamosal laterally, and 586 the pterygoid ventrally.

587 The anterior part of the opisthotic forms parts of the cavum labyrinthicum (Fig. 5C-D). On

588 the right opisthotic, the processus interfenestralis, which walls the cavum labyrinthicum

589 posteriorly, is broken off (Fig. 5A). On the left element, the process is also damaged, but still

590 preserved in articulation with the underlying pterygoid (Fig. 5C-D). The processus

591 interfenestralis is delicate in UMZC T1041, but resembles the process of Eilaenchelys

592 waldmanni (NMS.G.2004.31.15) and more crownward positioned stem-turtles by reaching

593 ventrally to fully separate the cavum labyrinthicum from the recessus scalae tympani. At the 
594 dorsal base of the processus interfenestralis, the lateral foramen for the glossopharyngeal nerve is

595 visible (Fig. 5A, C). The ventral end of the process is expanded to a small footplate that

596 articulates with the dorsal surface of the pterygoid, and frames the fenestra ovalis

597 posteroventrally (Fig. 5C-D). The footplate of the process also minimally contacts the

598 parabasisphenoid, which has a dorsally high margin surrounding the 'cup' that holds parts of the

599 brain. The processus interfenestralis is centrally broken on the left side of UMZC T1041,

600 probably where the fenestra perilymphatica minimized its structural integrity. Whereas the

601 ventral part with the footplate is in perfect articulation with the prootic and pterygoid, the dorsal

602 part of the process and the remainder of the left opisthotic are slightly misplaced with regard to

603 their original position. Although the fenestra perilymphatica is thus collapsed, there is no reason

604 to believe its size was smaller than that of other turtles, as sometimes stated for paracryptodires

605 and Pleurosternon bullockii specifically (e.g. Brinkman \& Nicholls, 1993; Gaffney, 1996; Joyce,

606 2007). Additionally, the perilymphatic foramen of Uluops uluops (UCM 53971) is of 'regular'

607 size, and the morphology of the processus interfenestralis of this taxon is very similar to that of

608 Pleurosternon bullockii. Laterally and slightly anteriorly to the base of the processus

609 interfenestralis of UMZC T1041, there is a shallow sulcus in the roof of the cavum acustico-

610 jugulare, the perilymphatic fossa, which continues anteriorly to become confluent with

611 respective fossa on the prootic (Fig. 5C). The presence of this sulcus, its connection to the

612 prootic fossa, and its posterior end at the base of the processus interfenestralis, and thus near the

613 recessus scalae tympani, provide further tentative evidence that the fossa indeed is associated to

614 the soft tissues that form an enclosed fluid-flow system between the fenestra ovalis, cavum

615 labyrinthicum, foramen perilymphatica, and recessus scalae tympani (e.g. Evers \& Benson,

616 2019; Foth et al., 2019). 
617 A large facet for the exoccipital spans over the posteromedial margin of the opisthotic (Fig.

618 5A). The facet extends posteriorly halfway along the paroccipital process, indicating that the

619 exoccipital had an elongate posterodorsolateral process. The size of the exoccipitals as inferred

620 from their opisthotic facets suggests that the recessus scalae tympani, which is posteriorly framed

621 by the exoccipital, was a large element. The dorsal margin of the foramen jugulare anterius is

622 visible as a gentle notch in the opisthotic's margin with the brain cavity (Fig. 5A) and located

623 just anterior to the facet for the exoccipital.

624 The paroccipital process of the opisthotic is relatively flat dorsoventrally (Figs. 2F, 5A), as in

625 Uluops uluops (UCM 53971), and has a thin edge posterior to the articulation facet for the

626 exoccipital. The lateral surface of the process lies against the quadrate and both are dorsally

627 overlapped by the squamosal.

628

629 Parabasisphenoid. The parabasisphenoid of turtles develops from the fusion of the

630 parasphenoid and basisphenoid (Sterli et al., 2010). Although some regin of the fused

631 parabasisphenoid can be attributed relatively safely to the original ossification centers, as

632 hypothesized by Sterli et al. (2010) for several taxa including Pleurosternon bullockii, the CT

633 scan of UMZC T1041 gives no indication as to where the suture between both ossifications lies.

634 Thus, the basisphenoid and parasphenoid are completely fused in UMZC T1041. In

635 consequence, we segmented the parabasisphenoid as a single element, and describe it as such

636 without distinguishing the parasphenoid and basisphenoid regions. The parabasisphenoid of

637 UMZC T1041 is completely preserved and contacts the pterygoid, prootic, opisthotic, and

638 basioccipital (Figs. 2B, 7). A contact with the exoccipital is not preserved, but cannot be ruled

639 out, as well as possible anterior contacts with the palatines or the vomer. The parabasisphenoid 
640 of Pleurosternon bullockii is anteroposteriorly elongate and mediolaterally narrow (Fig. 7). The

641 ventrally exposed surface of the parabasisphenoid is vaguely triangular, as the parabasisphenoid

642 narrows anteriorly to the rostrum basisphenoidale. Although the pterygoids are not in perfect

643 articulation with the parabasisphenoid in UMZC T1041, it seems that the ventral surface of the

644 rostrum basisphenoidale was exposed ventrally, separating the pterygoids and preventing them

645 from having a midline contact (see also Evans \& Kemp, 1975). Indication for this interpretation

646 comes from anteroposterior grooves to either side of the rostrum basisphenoidale (Fig. 7B),

647 which we interpret to be the articular facets of the pterygoid. The ventral surface of the

648 parabasisphenoid between these facets is completely smooth, just as the adjacent ventral surface

649 of the pterygoids, further support the notion that this bone was exposed. Conversely, parts of the

650 parabasisphenoid that are overlapped by the pterygoid are usually roughened by articular ridges

651 in comparative taxa like Uluops uluops (UCM 53971). A ventrally exposed rostrum

652 basisphenoidale has also been described for Glyptops ornatus (Gaffney, 1979a), but it remains

653 unclear, though plausible, if the pterygoids are fully separated by the parabasisphenoid in both

654 taxa.

655 At about half the length of the parabasisphenoid of UMZC T1041, the basipterygoid process

656 projects laterally from the ventrolateral margin of the bone (Fig. 7B-C, E). Although it has been

657 argued that the process on the lateral margin of the basisphenoid of UMZC T1041 does not

658 constitute a basipterygoid process (Gaffney, 1979a; Sterli et al., 2010), we agree with the original

659 identification of Evans \& Kemp (1975) and later assessments of the structure (e.g., Rabi et al.,

660 2013). The basipterygoid process is subdivided into a dorsal and a ventral flange by a deep

661 sulcus for the cerebral artery (Fig. 7E), which is also the case in Uluops uluops (UCM 53971).

662 The dorsal flange is likely homologous with the basipterygoid process of other turtles, as the 
663 carotid system extends ventrally to it. The cerebral artery canal of UMZC T1041 fully enters the

664 parabasisphenoid just anterior to the basipterygoid process via the foramen posterius canalis

665 carotici cerebralis (see also Sterli et al., 2010) and projects anteromedially through the bone (Fig.

666 7E). The dorsal flange of the basipterygoid process is larger, and inserts deeply into the

667 respective facet on the pterygoid. Anterior to the foramen posterius canalis carotici cerebralis,

668 there is a faint and narrow groove that extends along the ventrolateral surface of the rostrum

669 basisphenoidale. This groove is herein not interpreted as a narrow canal for the palatine artery, as

670 it is not mirrored in the pterygoid bone. Instead, the pterygoid would fill the groove when

671 articulated tightly with the parabasisphenoid. Thus, we herein interpret the groove as the

672 delimitation of the facet for the pterygoid (Fig. 7B, E). The palatine canal therefore appears to be 673 absent in UMZC T1041.

674 A peculiar feature of the basicranium of UMZC T1041 is the presence of a posterior process

675 jointly formed by the parabasisphenoid and pterygoid (Fig. 7B-C, E), which overlaps the ventral 676 surface of the basioccipital. The parabasisphenoid part of this process is larger and more distinct 677 than the pterygoid part. In UMZC T1041, the ventral surface of the posterior parabasisphenoid 678 processes is slightly raised, and forms a shallowly concave fossa between them. Additionally, the 679 surface of the process is textured by a short ridge. Such parabasisphenoid processes are also 680 present in Glyptops ornatus (Gaffney, 1979a) and Uluops uluops (UCM 53971), and could be a 681 pleurosternid synapomorphy. Posterolaterally projecting processes of the parabasisphenoid are 682 also present in some baenids, such as Eubaena cephalica (Rollot, Lyson \& Joyce, 2018), but the 683 baenid process has less external relief, and seems better integrated into a flat ventral surface of 684 the basicranium. Similar structures are also found in helochelydrids, in which these are 685 sometimes referred to as a secondarily pair of tubercula basioccipitale (Joyce, Sterli \& Chapman, 
686 2014). In helochelydrids, these anterior tubercula basioccipitale are predominantly formed by the 687 pterygoids (Naomichelys speciosa: Joyce, Sterli \& Chapman, 2014), or entirely formed by the 688 pterygoids (Helochelydra nopscai: Joyce et al., 2011). Despite these differences in composition 689 of the processes, the anterior tubercula basioccipitale of helochelydrids and the posterior 690 parabasisphenoid processes of pleurosternids share (i) that the posterior margin between them is 691 concave; (ii) that they are slightly raised and form a concavity medially between them; (iii) that 692 they overlap the basioccipital; and (iv) that their surface is textured indicating soft tissue 693 insertion. Thus, topological and anatomical arguments suggest the homology of the pleurosternid 694 and helochelydrid processes, and possibly provide evidence for paracryptodiran affinities of 695 helochelydrids (see also Joyce, 2017; Joyce \& Anquetin, 2019). To highlight this possible 696 homology, we follow Joyce, Sterli \& Chapman (2014) by calling these processes (anterior) 697 tubercula basioccipitale (Fig. 7).

698 The dorsal surface of the parabasisphenoid of UMZC T1041 is extremely similar to the same 699 surface in Uluops uluops (UCM 53971) and YPM 4717, a specimen referred to Glyptops 700 plicatulus by Gaffney (1979a) (Glyptops ornatus according to taxonomy followed here) based on 701 temporal and geographic reasoning. It can be divided into a posterior, slightly cup-like region 702 that holds parts of the brain, and the rostrum basisphenoidale anteriorly (Fig. 7A). In the 703 posterior region, the parabasisphenoid is dorsoventrally thickest. The posterolateral margin of the 704 parabasisphenoid is dorsally expanded. This expansion, which is also present in Uluops uluops 705 (UCM 53971), forms the ventral margin of the hiatus acusticus (Fig. 7A) and contacts the 706 processus interfenestralis of the opisthotic posteriorly and the prootic anteriorly (Fig. 5D). The 707 lateral margins of the parabasisphenoid anterior to the hiatus acusticus margin are gently raised, 708 so that the medial space between is transversely concave (Fig. 7A). The concavity is interrupted 
709 posteriorly by a shallow basis tuberculi basalis (Fig. 7A, D), which would presumably have

710 continued posteriorly onto the basioccipital, as seen in Uluops uluops (UCM 53971). Foramina

711 for the abducens nerve are present anterolaterally on the dorsal parabasisphenoid surface. The

712 respective anterior foramina exit on the anterior basisphenoid surface within the retractor bulbi

713 pits ventral to the clinoid processes. The clinoid processes at the anterolateral corner of the

714 parabasisphenoid cup are extremely short (Fig. 7A, D), as is also the case in Uluops uluops

715 (UCM 53971). The dorsum sellae between the clinoid processes of UMZC T1041 is not

716 developed as a vertical wall, but also not as a horizontal sheet that overlaps the sella turcica.

717 Instead, the dorsum sellae is only a very minor, shallow ridge (Evans \& Kemp, 1975; Fig. 7D).

718 Ventrally underneath the ridge, the anterior surface of the parabasisphenoid slopes toward the

719 rostrum basisphenoidale and sella turcica. This anterior surface is gently depressed and a midline

720 ridge is absent (Fig. 7D). The lateral aspects of the anterior surface are delimited by short vertical

721 ridges that extend from the base of the clinoid process downwards. These ridges also define deep

722 retractor bulbi pits directly ventral to the clinoid processes (Fig. 7D). The retractor bulbi pits are

723 further accentuated dorsally by a horizontal ridge at the base of the clinoid process, which is the

724 same in Glyptops ornatus (Gaffney, 1979a). In Uluops uluops (UCM 53971), the anterior surface

725 of the parabasisphenoid varies from Glyptops ornatus and Pleurosternon bullockii in lacking

726 distinct retractor bulbi pits and having a deeper anterior surface ventral to the dorsum sellae. The

727 rostrum basisphenoidale of UMZC T1041 extends anteriorly as a mediolaterally narrow sheet of

728 bone. Its lateral margins are dorsally upturned, so that the sella turcica is well defined as a deep

729 fossa (Fig. 7A, D). In the posterior margin of the sella turcica, the paired foramina anterius

730 canalis carotici cerebralis are situated in relatively close proximity to one another (Fig. 7D). 
732 Stapes. The stapes are not preserved for UMZC T1041.

733

734 Carotid circulation and facial nerve. Unambiguous osteological correlates are present in

735 UMZC T1041 for the cerebral artery, the (undivided) facial nerve, and both major distal

736 branches of the facial nerve, which are the hyomandibular and vidian nerves. As there is no

737 evidence for a palatine artery canal, the palatine artery is either absent, or uncovered by bone, but

738 located in an unusual position.

739 As described above (see parabasisphenoid), the basipterygoid process of UMZC T1041 is

740 subdivided into a dorsal and a ventral flange (Fig. 7B-C, E), between which the canal for the

741 cerebral artery starts to pierce the parabasisphenoid (Fig. 7E). This region is ventrally exposed,

742 as the parabasisphenoid and pterygoid form a window-like recess around the basipterygoid

743 articulation. No canalis caroticus internus is present posterior to the position of the basipterygoid

744 process, so that the internal carotid artery is not embedded in bone (see also Sterli et al., 2010).

745 As the ventral flange of the basipterygoid process is much smaller than the dorsal flange, the

746 artery can enter the basicranium via the small fenestra between the pterygoid and

747 parabasisphenoid. As the artery directly enters the parabasisphenoid in this position, we do not

748 classify this opening within the basipterygoid articulation as a foramen posterius canalis carotici

749 interni (as done in Evans \& Kemp, 1975), but as the foramen posterius canalis carotici cerebralis

750 (as in Sterli, 2010). The palatine artery canal, if present, would be expected to extend anteriorly

751 between the pterygoid and parabasisphenoid from the position of the foramen posterius canalis

752 carotici cerebralis. Gaffney (1979a) indicated the presence of such a canal for Glyptops ornatus,

753 but this should be revisited, as he did not find the anterior foramen for the palatine artery canal

754 and thus might have misidentified the foramen for the vidian canal. In UMZC T1041, no palatine 
755 artery canal can be discerned. The parabasisphenoid, which is slightly disarticulated from the left

756 pterygoid and strongly so from the right one, shows a subtle and narrow groove, that extends

757 from the foramen posterius canalis carotici cerebralis forward and could thus be a candidate

758 structure for the palatine artery canal (Fig. 7B). However, when the pterygoid is articulated, the

759 respective groove is 'closed' by bone of the pterygoid, so that the groove likely constitutes a

760 pterygoid facet, rather than a tiny canalis caroticus palatinum. As the posterior course of the

761 internal carotid artery prior to its 'split' is not embedded in bone, the absence of the palatine

762 artery canal does not necessarily warrant concluding that the artery itself is absent. However, as

763 there is no indication of an interpterygoid slit or similar opening through which the palatine

764 artery could eventually enter the cranium in UMZC T1041 or related taxa with more completely

765 preserved anterior palate regions, the most parsimonious explanation of the observed pattern

766 indeed is the loss of the palatine artery. The loss of the palatine artery has also been inferred for

767 other paracryptodires (Gaffney, 1975a; Lipka et al., 2006), including baenids (Rollot, Lyson \&

768 Joyce, 2018). However, the absence does not seem universal, as Uluops uluops clearly shows a

769 palatine artery canal (UCM 53971). A palatine artery canal has also been reported for

770 Dorsetochelys typocardium by Anquetin and André (2020), but these authors do not describe the

771 canal system in detail and it thus remains unclear if the proposed palatine artery canal foramen

772 reported for Dorsetochelys typocardium is indeed that or pertains to the canal system of the

773 vidian nerve. Indeed, the posterior entry of the palatine artery described by Anquetin and André

774 (2020) resembles that of the vidian canal described herein for Pleurosternon bullockii by

775 piercing the pterygoid. As the situation in Dorsetochelys typocardium demands clarification,

776 ideally by means of CT scanning, we will not further comment on this taxon herein. The

777 condition of Uluops uluops (UCM 53971) is very similar to that Pleurosternon bullockii by 
778 having the carotid canal enter within a bifurcated basipterygoid process, although the former also

779 has a foramen for the palatine artery. Uluops uluops (UCM 53971) shows, that no part of its

780 internal carotid artery up to the point of its division is embedded by bone. In Arundelemys

781 dardeni, the internal carotid artery itself is also not encased anteriorly, the palatine artery is

782 absent, and the entry of the cerebral artery canal lies within a shallow fossa between the

783 parabasisphenoid and pterygoid. All these turtles differ from baenids, in which the anterior part

784 of the internal carotid artery is concealed by bone. This embedding of the internal carotid artery

785 in baenids extends posteriorly up to the intersection of the carotid artery system with the canalis

786 pro ramo nervi vidiani (Rollot, Lyson \& Joyce, 2018). On the other hand, similarities between

787 baenids, Pleurosternon bullockii, and Arundelemys dardeni exist in their shared absence of a

788 palatine artery. Thus, most paracryptodires show similarities to one another in their carotid artery

789 system, but lots of within-group variation exists that can probably only be better understood once

790 the phylogenetic relations of these turtles are better characterized.

791 The facial nerve of UMZC T1041 exits the braincase laterally through the canalis nervus

792 facialis, which extends from the fossa acustico-facialis through the prootic and into the canalis

793 cavernosus. The position of the geniculate ganglion can be inferred to be within the canalis

794 cavernosus for UMZC T1041, because direct osteological evidence for the course of the

795 hyomandibular and vidian nerves begin there: the prootic has a hyomandibular sulcus that

796 extends from the lateral facial nerve canal foramen posteriorly to the cavum acustico-jugulare

797 (Fig. 7B). The vidian nerve passes ventrally through the pterygoid via the canalis pro ramo nervi

798 vidiani, which exits just posterior to the pterygoid ridge that borders the area of the basipterygoid

799 articulation (Fig. 7C). In turtles with an embedding of the internal carotid artery, the canalis pro

800 ramo nervi vidiani usually leads from the canalis cavernosus into the internal carotid canal (e.g. 
801 Gaffney, 1979b). In UMZC T1041, which lacks an internal carotid canal, the vidian nerve is thus

802 transmitted to the ventral surface of the basicranium. From here, it is inferred to pass between the

803 dorsal and ventral flanges of the basipterygoid process, together with the carotid artery. Within

804 the facet for the basipterygoid process, the vidian nerve then enters the canalis nervus vidianus,

805 which starts in the center of the facet and extends anteriorly through the pterygoid. This posterior

806 foramen for the vidian canal was interpreted as a foramen posterius canalis carotici palatinum by

807 Sterli et al. (2010). However, the canal extends through the pterygoid only, instead of passing

808 along the parabasisphenoid-pterygoid suture, and exits anterolaterally from the sulcus cavernosus

809 (Fig. 6B, C), instead within the sulcus itself. Thus, the course and exit foramen of the canal

810 conform to the expectations of a canalis nervus vidianus (Rollot, Lyson \& Joyce, 2018).

811

812 DISCUSSION

813 Paracryptodiran monophyly. The fossil turtle clade Paracryptodira was initially proposed

814 based on the anterior position of the foramen posterius canalis carotici interni halfway along the

815 contact of the basisphenoid with the pterygoid, in contrast to pleurodires, which have an entry

816 that involved the prootic and/or quadrate, and crown cryptodires, which have an entry towards

817 the posterior margin of the pterygoid (Gaffney, 1975a). The accuracy and utility of this character

818 has been debated ever since (e.g., Evans \& Kemp, 1976; Gaffney, 1979a; Rieppel, 1980; Sterli et

819 al., 2010; Rabi et al., 2013), but progress has been hampered by confusing terminology and

820 conflicting observations.

821 Our study suggests that two distinct morphotypes are present among paracryptodires.

822 Whereas an anteriorly positioned foramen posterius canalis carotici interni indeed seems to be

823 present in Compsemys victa (UCM 53971) and Eubaena cephalica (Rollot, Lyson \& Joyce, 
824 2018), this foramen is not present in Pleurosternon bullockii (UMZC T1041) and Uluops uluops

825 (UCM 53971), as the internal carotid artery is embedded in bone in these taxa. This difference

826 was initially disguised by terminology used from the 1970s to early 2000 s, as the foramen

827 posterius canalis carotici cerebralis was addressed as the foramen posterius canalis carotici

828 interni (Rabi et al., 2013). Homology can nevertheless be maintained, if the foramen posterius

829 canalis carotici interni is conceptualized as the entry to a small pit at the basisphenoid/pterygoid

830 suture from which the cerebral and palatine arteries penetrate the surrounding bones, as had been

831 reported for several paracryptodires, including Glyptops ornatus (Gaffney, 1979) or

832 Pleurosternon bullockii (Sterli et al., 2010), but we are here able to demonstrate that this

833 character concept is at least inapplicable to the latter, as the palatal canal is absent.

834 The above-listed differences should not be used to dismiss the fact that the carotid system, in 835 general, enters the skull in all known paracryptodires from below relatively far anteriorly at or

836 near the basisphenoid/pterygoid suture. Indeed, as the exact vessels penetrating the skull could 837 only rarely be assessed prior to the use of CT scanning technology, we suspect from personal 838 experience (WGJ) that the paracryptodiran condition was conceptualized by most authors by 839 reference to topology, not the exact vessels that enter the skull. This broadened character 840 concept, however, still pertains to two unrelated morphological aspects: first, the anterior

841 placement of the entry of the carotid system and, second, the presence of an extended

842 basisphenoid-pterygoid contact. The (derived) presence and extent of the basisphenoid-pterygoid

843 contact is addressed in current phylogenetic analyses by other characters (e.g. Joyce, 2007;

844 Sterli, 2010; Anquetin, 2012; Zhou \& Rabi, 2015; Evers \& Benson, 2019), while the

845 (plesiomorphic) anterior placement of the carotid system entry could be grouped with the

846 condition seen in basal turtles. So, while these two morphological aspects combined indeed 
847 diagnose paracryptodires relative to most other turtles, they are redundant with existing

848 characters. We therefore here further support recent phylogenetic analysis (e.g. Evers \& Benson,

8492019 ) by suggesting that the 'paracryptodiran condition' should not be utilized as a carotid

850 arterial character.

851 Although the most important 'paracryptodiran' cranial character can thus be debunked,

852 pleurosternids, baenids, and other potential paracryptodires share several features that could 853 potentially support their monophyly. In addition to the sculpturing of the shell (present in early

854 baenids; e.g. Gaffney, 1972; Joyce \& Anquetin, 2019), baenids and pleurosternids share some

855 gross resemblance in their maxilla-premaxilla morphology, including a relatively strongly curved

856 labial margin of the maxilla and a notch in the median section of the labial ridge along the

857 premaxilla (Gaffney, 1972). Additionally, the jugal is dorsally removed from posteriorly

858 continuing the labial ridge otherwise formed by the maxilla (Gaffney, 1972). These features are,

859 however, not unique to paracryptodires, as they also appear in extant turtles with ecologies that

860 are probably similar to those of paracryptodires, such as riverine geoemydids (e.g. Gaffney,

861 1979b). To critically assess potential new paracryptodiran synapomorphies, the skulls of early

862 baenids, particularly Trinitichelys hiatti, should be re-described.

863

864 Paracryptodiran relationships. This contribution is part of a larger study that attempts to better 865 resolve the internal and external relationships of paracryptodires, if monophyletic, through a

866 better understanding of their anatomy. Although the novel observations we made herein will be

867 processed in later contributions, we take the liberty of highlighting similarities that particularly

868 intrigue us and that may have phylogenetic significance. 
869 Irrespective of paracryptodiran monophyly, our description of Pleurosternon bullockii

870 provides morphological evidence for the content of Pleurosternidae, based on instances of

871 similarities of Pleurosternon bullockii with some other taxa. Although a re-description of

872 Glyptops ornatus is warranted to fully appreciate its anatomy, it is clear from existing

873 information (e.g. Gaffney 1979a) that this taxon is indeed very similar to Pleurosternon

874 bullockii, both in terms of general skull form, and in more detailed anatomical aspects. For

875 instance, Pleurosternon bullockii and Glyptops ornatus share the following features: small

876 prefrontals; long anterior processes of the frontals that partially separated the nasals; a

877 squamosal-parietal contact; dorsal position of the jugal above the level of the labial margin of the

878 maxilla; and, among other similarities in the parabasisphenoid morphology, the presence of

879 anterior tubercula basioccipitale, the presence of a basipterygoid process, and the presence of

880 deep retractor bulbi pits. The same is generally true for Dorsetochelys typocardium, in particular

881 the jugal exclusion from the orbit (DORCM G.00023; contra Evans \& Kemp 1976) and the

882 presence of anterior tubercula basioccipitale (DORCM G.00023; not discernible in Evans \&

883 Kemp 1976). In both cases, these similarities are not surprising, given that more recent

884 phylogenetic hypotheses already highlight close relationships among these turtles (e.g. Pérez-

885 García, Royo-Torres \& Cobos, 2015; Joyce \& Rollot, in press).

886 Although the skull of Uluops uluops deviates in general aspects of its cranial shape, we note a 887 great number of similarities between this taxon and Pleurosternon bullockii. Although Uluops 888 uluops has so far not been considered a pleurosternid (e.g. Carpenter \& Bakker, 1990; Lyson \& 889 Joyce 2011, Pérez-García, Royo-Torres \& Cobos, 2015; Joyce and Rollot, in press), our 890 comparisons indicate that it might be attributable to this clade. Among the features that are 891 shared between Uluops uluops and Pleurosternon bullockii are a squamosal-parietal contact 
892 (possibly plesiomorphically present in baenids; Gaffney 1972); the exclusion of the prootic from

893 the trigeminal foramen by a posteroventral ramus of the parietal (also present in

894 thalassochelydians and sandownids; Anquetin, Püntener \& Joyce, 2017; Evers \& Joyce, 2020);

895 the presence of an extended sulcus palatino-pterygoideus formed in part by an enlarged septum

896 orbitotemporale (

897 Meylan, 2006); presence of a deep fossa in the roof of the sulcus palatino-pterygoideus (also in

898 pleurodires; Gaffney, Tong \& Meylan, 2006); dorsal position of the jugal above the level of the

899 labial margin of the maxilla (also present in baenids; Gaffney 1972); the size and shape of the

900 quadratojugal; the presence of a small quadrate-supraoccipital contact (unclear in early baenids);

901 the complete surrounding of the fenestra ovalis by the prootic and opisthotic (absent in

902 Arundelemys dardeni [USNM 41614]; unclear in other early baenids); the presence of a

903 hyomandibular nerve sulcus in the posterior part of the canalis cavernosus (unclear in early

904 baenids); the presence of anterior tubercula basioccipitale (shared also with helochelydrids, see

905 below); the presence of a basipterygoid process that is laterally invaded by the cerebral artery

906 (absent in baenids and Compsemys victa, but symplesiomorphic for turtles); and the general

907 shape of the parabasisphenoid (see description for full details). Although some of these

908 characters may prove to be more widespread among paracryptodires in particular or stem-turtles

909 more generally, the number of similar features between Pleurosternon bullockii and Uluops

910 uluops lend support to the hypothesis that the latter is a pleurosternid.

911 We here also document intriguing similarities between Pleurosternon bullockii and

912 helochelydrids, particularly in the anterior tubercula basioccipitale of the parabasisphenoid, but

913 also in other features, such as the exclusion of the jugal from the orbit (e.g. Joyce et al., 2011;

914 Joyce, Sterli \& Chapman, 2014; Joyce 2017). Helochelydrids should be integrated into 
915 phylogenies with a dense sampling of paracryptodires to test if they are more closely related than 916 currently thought.

917 We also note the presence of some features in Pleurosternon bullockii that are possibly more 918 widespread among crownward stem-turtles than previously recognized, and which can therefore 919 possibly aid in better constraining the global position of pleurosternids. For instance, a 920 pterygoid-basioccipital contact has previously not universally been recognized in pleurosternids 921 (but see Gaffney, 1979a). This feature, considered diagnostic for baenids (Joyce \& Lyson, 2015),

922 is present in Pleurosternon bullockii and Uluops uluops (as well as in compsemydids and 923 helochelydrids). Although thus probably widely present among paracryptodires, this feature 924 probably cannot serve as a paracryptodiran synapomorphy, as several other clades that have 925 repeatedly been hypothesized to be crownward stem turtles (e.g. Joyce 2007), including 926 thalassochelydians, protostegids, and some xinjiangchelyids, also possess a pterygoid-

927 basioccipital contact (Brinkman et al., 2013; Anquetin, Püntener \& Joyce, 2017; Evers, Barrett \& 928 Benson, 2019). Conversely, we here demonstrate that a purported thalassochelydian 929 synapomorphy, the presence of a posteroventral process of the parietal along the posterior 930 margin of the trigeminal foramen (Anquetin, Püntener \& Joyce, 2017), is also present in

931 Pleurosternon bullockii (and also Uluops uluops). The two examples of the pterygoid-

932 basioccipital contact and the presence of a posteroventral parietal process are a nice 933 demonstration of how alleged synapomorphies or diagnostic features of relatively inclusive 934 groups can have a much wider distribution across phylogeny. This highlights (i) the importance 935 of detailed descriptive work to acknowledge the anatomical variation present across several 936 clades; and (ii) the importance of global phylogenetic approaches to the classification of fossil937 only turtle clades. The latter is because the character state distribution outside the 'focal clade' 
938 has importance not only for inference of global phylogenetic placements, but also has an effect

939 on in-group relationships and the optimization and polarity of characters (e.g. Kluge \& Farris,

940 1969; Farris, 1972; Nixon \& Carpenter, 1993). The distribution of the pterygoid-basioccipital

941 contact, for instance, indicates that rather than being a local baenid synapomorphy, it possibly

942 represents a synapomorphy of the clade that includes paracryptodires but also other probable

943 crownward stem-turtle clades (e.g. Evers \& Benson, 2019) such as xinjiangchelyids or

944 thalassochelydians. On the other hand, studies focused on more inclusive focal groups without a

945 global phylogenetic perspective often sample characters that document variation among the

946 suspected clade members to a finer level of detail than done in most global studies (e.g. Joyce \&

947 Lyson, 2011, for paracryptodires). We think that it is important to reconcile the finer-level

948 studies with global phylogenetic approaches to address questions such as: do baenids and

949 paracryptodires form a monophylum?; or what is the global position of these clades? We hope

950 that detailed anatomical studies such as the one presented here lead to the recognition of new

951 phylogenetic characters as well as the revision of those that have been used in the past, so that

952 the outlined questions can be more comprehensively addressed in the future.

953 On a final note, we find that Pleurosternon bullockii shows some remarkable similarities with

954 pleurodire turtles, particularly in the orbitotemporal region of the skull, as well as the external

955 process of the pterygoid. However, the orbitotemporal region of most fossil turtles is not

956 sufficiently described to draw meaningful comparisons from the literature alone. CT scans of

957 several specimens available to us, such as the xinjiangchelyid Annemys sp. (IVPP V18106;

958 specimen described in Brinkman et al. [2013]), the probable sandownid Solnhofia parsonsi (TM

959 4023; specimen described in Gaffney [1975b]) or the plesiochelyid Plesiochelys planiceps

960 (OUMNH J1582; specimen described in Gaffney [1976]) show that a strong ventral ridge of the 
961 postorbital that would form the septum orbitotemporale and define a narrow sulcus palatino-

962 pterygoideus is absent in these turtles. This indicates that the similarity observed between

963 Pleurosternon bullockii and pleurodires in regard to the septum interorbitale and related sulcus

964 palatino-pterygoideus is unique, and not more widespread across the turtle stem. Similarly, the

965 pleurodire-reminiscent morphology of the external pterygoid process of Pleurosternon bullockii

966 is not seen in other crownward stem-turtles: the vertical flange of the external process of the

967 pterygoid of Pleurosternon bullockii is comparatively larger than that of plesiochelyids or

968 Annemys sp. Although both the size of the vertical flange and its slight medial deflection at the

969 dorsal margin in Pleurosternon bullockii establishes some similarity to the pterygoid trochlea of

970 pleurodires, important differences remain. For instance, the surface of the vertical flange of the

971 external pterygoid process is oriented parallel to the sagittal skull plane, and not posterolaterally

972 inclined. Unfortunately, the morphology of the pterygoid trochlea is unknown for stem-

973 pleurodires (De Lapparent de Broin, de la Fuente \& Fernandez, 2007), but a gradual evolution of

974 the pterygoid adductor musculature system via a double-trochlea along the external pterygoid

975 process and the otic capsule has been proposed as a possible evolutionary scenario (e.g. Joyce,

976 2007). Although the presence of a double trochlea does not seem to provide biomechanical

977 advantages according to analytical studies (Ferreira et al., 2020), all hypotheses for the evolution

978 of the pleurodire trochlea invoke a size increase of the external pterygoid process and its lateral

979 surface as an initial step (e.g. Joyce, 2007; Joyce \& Sterli, 2012; Ferreira et al., 2020). Although,

980 at this point in time, we do not hypothesize that pleurosternids are stem-pleurodires, the

981 similarities noted herein should be further explored by additional comparisons and phylogenetic

982 implementation. 


\section{CONCLUSIONS}

985 The cranial anatomy of Pleurosternon bullockii and comparative descriptions confirm high

986 levels of similarity with other hypothesized pleurosternids, such as Glyptops ornatus or

987 Dorsetochelys typocardium. Additionally, we note a large number of similarities between

988 Pleurosternon bullockii and Uluops uluops, which possibly is a pleurosternid as well. Among

989 other features, these taxa share a similar basipterygoid region, with the symplesiomorphic

990 retention of a basipterygoid process and a ventrally unimbedded internal carotid artery course,

991 shared with earlier diverging stem-turtles. These features, along with a relatively extensive dorsal

992 skull coverage and weakly developed otic trochleae, support the hypothesis that pleurosternids

993 are globally positioned among an extended stem-lineage of turtles. Our anatomical description of

994 Pleurosternon bullockii provides tentative evidence for close relationships between

995 pleurosternids and helochelydrids, which share unusual posterior processes of the

996 parabasisphenoid that form a second set of (anterior) tuberculae basioccipitale.

997 Although variation regarding the internal carotid region of the cranium exists among

998 pleurosternids, it is clear that the anterior position of the foramen posterius canalis carotici

999 interni, historically used as a synapomorphy to unite baenids and pleurosternids as

1000 Paracryptodira, is not present in pleurosternids, and results from misinterpretation of the

1001 respective anatomy. As other paracryptodiran cranial synapomorphies are also dubious, our

1002 observations challenge previous observations upon which traditional hypotheses regarding the

1003 systematics of paracryptodires were built. Although the monophyly of paracryptodires is thus

1004 currently not supported by evidence from cranial anatomy, CT documentation of early baenid

1005 cranial morphology is outstanding, and may provide such evidence in the future. 
1007

1008

1009

1010

1011

1012

1013

1014

1015

1016

1017

1018 NMS

1019

1020

1021

1022

1023

1024

1025 TM

1026

1027

1028

seen in the area between the otic and temporal fossae. The formation of a relatively narrow sulcus palatino-pterygoideus by an expanded septum orbitotemporale is unparalleled in other crownward stem-turtles such as xinjiangchelyids or thalassochelydians. An expanded external pterygoid process with a dorsomedially deflected vertical flange also approaches the pleurodiran morphology. Further investigations are necessary to test if this morphology could be a model for an ancestral pleurodiran pterygoid trochlea.

\section{INSTITUTIONAL ABBREVIATION}

DORCM Dorset County Museum, Dorchester, United Kingdom.

IVPP Institute of Vertebrate Paleontology and Paleoanthropology, Chinese Academy of Sciences, Beijing, People's Republic of China.

NMS National Museum of Scotland, Edinburgh, United Kingdom

OUMNH Oxford University Museum of Natural History, University of Oxford, Oxford, United Kingdom.

UCM Museum of Natural History, University of Colorado, Boulder, Colorado, USA.

UMZC Museum of Zoology, Cambridge University, Cambridge, United Kingdom.

USNM United States National Museum, Smithsonian Institution National Museum of Natural History, Washington, D.C., USA.

TM Teylers Museum, Haarlem, The Netherlands.

YPM Yale Peabody Museum of Natural History, New Haven, Connecticut, USA.

\section{ACKNOWLEDGEMENTS}


1029 We thank Roger Benson (University of Oxford) for scanning the cranium of UMZC T1041 in 1030 our stead. Keturah Smithson is thanked for maintaining the scanner at the Cambridge

1031 Biotomography Center and Jason Head (University of Cambridge) is acknowledged for 1032 permission to study the specimen. We also thank Gabriel Ferreira, Olivier Rieppel, and Julien 1033 Claude for three reviews that helped to improve a previous version of this manuscript, and we 1034 thank Fabien Knoll for the editorial oversight of our submission. Particular thanks to Gabriel 1035 Ferreira for spotting a segmentation mistake that would have been annoying if it had been 1036 published. The work is supported by a grant from the Swiss National Science Foundation (SNF 1037 200021_178780/1).

1038

1039 REFERENCES

1040 Anquetin J. 2012. Reassessment of the phylogenetic interrelationships of basal turtles

1041 (Testudinata). Journal of Systematic Palaeontology 10(1):3-45.

1042 Anquetin J, Püntener C, Billon-Bruyat J-P. 2015. Portlandemys gracilis n. sp., a new coastal 1043 marine turtle from the Late Jurassic of Porrentruy (Switzerland) and a reconsideration of 1044 plesiochelyid cranial anatomy. PLOS ONE 10(5): e0129193.

1045 Anquetin J, André C. 2020. The last surviving Thalassochelydia - a new turtle cranium from 1046 the Early Cretaceous of the Purbeck Group (Dorset, UK). PaleorXiv. 1047 doi:10.31233/osf.io/7pa5c.

1048 Anquetin J, Püntener C, Joyce WG. 2017. A review of the fossil record of turtles of the clade 1049 Thalassochelydia. Bulletin of the Peabody Museum of Natural History 58(2):317-369. 
1050 Brinkman DB, Nicholls EL. 1993. The skull of Neurankylus eximius (Testudines: Baenidae)

1051

1052

1053

1054

1055

1056

1057

1058

1059

1060

1061

1062

1063

1064

1065

1066

1067

1068

1069

1070

and a reinterpretation of the relationships of this taxon. Journal of Vertebrate Palaeontology

13(3):273-281.

Brinkman DB, Everth DA, Xu X, Clark JM, Wu X-C. 2013. Turtles from the Jurassic Shishugou Formation of the Junggar Basin, People's Republic of China, with comments on the basicranial region of basal eucryptodires. In: Brinkman et al., eds. Morphology and Evolution of Turtles. Dordrecht: Springer Science+Buisness Media, 147-172.

Cadena EA, Parham JF. 2015. Oldest known marine turtle? A new protostegid from the Lower Cretaceous of Colombia. PaleoBios 32:1-42.

Carpenter K, Bakker RT. 1990. A new latest Jurassic vertebrate fauna, from the highest levels of the Morrison Formation at Como Bluff, Wyoming. Part II. A new baenid turtle. Hunteria 2(6): 1-19.

De Lapparent de Broin F, de la Fuente MS, Fernandez MS. 2007. Notoemys laticentralis (Chelonii, Pleurodira), Late Jurassic of Argentina: new examination of the anatomical structures and comparisons. Revue de Paléobiologie 26(1):99-136.

Evans J, Kemp TS. 1975. The cranial morphology of a new Lower Cretaceous turtle from Southern England. Palaeontology 18(1):25-40.

Evans J, Kemp TS. 1976. A new turtle skull from the Purbeckian of England and a note on the early dichotomies of cryptodire turtles. Palaeontology, 19(2):317-324.

Evers SW. 2020. Project: Cranial CT scans of Pleurosternon bullockii. MorphoSource. Available at: https://www.morphosource.org/Detail/ProjectDetail/Show/project_id/1001

Peer] reviewing PDF | (2020:04:48267:1:0:NEW 22 May 2020) 
1071 Evers SW, Benson RBJ. 2019. A new phylogenetic hypothesis of turtles with implications for

1072 the timing and number of evolutionary transitions to marine lifestyles in the group.

1073 Palaeontology 62(1):93-134.

1074 Evers SW, Joyce WG. 2020. A re-description of Sandownia harrisi (Testudinata: Sandownidae)

1075 from the Aptian of the Isle of Wight based on computed tomography scans. Royal Society

$1076 \quad$ Open Science 7:191936.

1077 Evers SW, Barrett PM, Benson RBJ. 2019. Anatomy of Rhinochelys pulchriceps

1078 (Protostegidae) and marine adaptation during the early evolution of chelonioids. PeerJ

$1079 \quad 7: \mathrm{e} 6811$.

1080 Evers SW, Neenan JM, Ferreira GS, Werneburg I, Barrett PM, Benson RBJ. 2019.

1081 Neurovascular anatomy of the protostegid turtle Rhinochelys pulchriceps and comparisons of

1082 membranous and endosseous labyrinth shape in an extant turtle. Zoological Journal of the

$1083 \quad$ Linnean Society 187:800-828.

1084 Farris JS. 1972. Estimating phylogenetic trees from distance matrices. American Naturalist

1085 106:645-668.

1086 Ferreira GS, Lautenschlager S, Evers SW, Pfaff C, Kriwet J, Raselli I, Werneburg I. 2020.

1087 Feeding biomechanics suggests progressive correlation of skull architecture and neck

1088 evolution in turtles. Scientific Reports 10:5505.

1089 Foth C, Evers SW, Joyce WG, Volpato V, Benson RBJ. 2019. Comparative analysis of the

1090 shape and size of the middle ear cavity of turtles reveals no correlation with habitat ecology.

1091 Journal of Anatomy 235: 1078-1097.

1092 Gaffney ES. 1972. The systematics of the North American family Baenidae (Reptilia,

1093 Cryptodira). Bulletin of the American Museum of Natural History 147(5):241-320. 
1094 Gaffney ES. 1975a. A phylogeny and classification of the higher categories of turtles. Bulletin 1095 of the American Museum of Natural History 155(5):387-436.

1096 Gaffney ES. 1975b. Solnhofia parsonsi, a new cryptodiran turtles from the Late Jurassic of 1097 Europe. American Museum Novitates 2576:1-25.

1098 Gaffney ES. 1976. Cranial morphology of the European Jurassic turtles Portlandemys and 1099 Plesiochelys. Bulletin of the American Museum of Natural History 157(6):487-544.

1100 Gaffney ES. 1979a. The Jurassic turtles of North America. Bulletin of the American Museum of $1101 \quad$ Natural History 162(3):91-136.

1102 Gaffney ES. 1979b. Comparative cranial morphology of Recent and fossil turtles. Bulletin of the 1103 American Museum of Natural History 164(2):65-376.

1104 Gaffney ES. 1990. The comparative osteology of the Triassic turtle Proganochelys. Bulletin of 1105 the American Museum of Natural History, 194:1-263

1106 Gaffney ES. 1996. The postcranial morphology of Meiolania platyceps and a review of the 1107 Meiolaniidae. Bulletin of the American Museum of Natural History 229:1-166.

1108 Gaffney ES, Meylan PA. 1988. A phylogeny of turtles. In: Benton MJ, ed. The Phylogeny and 1109 Classification of the Tetrapods, Volume 1: Amphibians, Reptiles, Birds, Systematics

1110 Association Special Volume 35A. Oxford: Clarendon Press, 157-219.

1111 Gaffney ES, Tong H, Meylan PA. 2006. Evolution of the side-necked turtles: The families 1112 Bothremydidae, Euraxemydidae, and Araripemydidae. Bulletin of the American Museum of $1113 \quad$ Natural History 300:3-698.

1114 Gaffney ES, Rich TH, Vickers-Rich P, Constantine A, Vacca R, Kool L. 2007. Chubutemys, 1115 a new eucryptodiran turtles from the Early Cretaceous of Argentina, and the relationships of 1116 the Meiolaniidae. American Museum Novitates 3599:1-35. 
1117 Joyce WG. 2007. Phylogenetic relationships of Mesozoic turtles. Bulletin of the Peabody

1118 Museum of Natural History 48(1):3-102.

1119 Joyce WG. 2017. A review of the fossil record of basal Mesozoic turtles. Bulletin of the

1120 Peabody Museum of Natural History 58(1):65-113.

1121 Joyce WG, Anquetin J. 2019. A review of the fossil record of nonbaenid turtles of the clade

1122 Paracryptodira. Bulletin of the Peabody Museum of Natural History 60(2): 129-155.

1123 Joyce WG, Lyson TR. 2015. A review of the fossil record of turtles of the clade Baenidae.

1124 Bulletin of the Peabody Museum of Natural History 56(2):147-183.

1125 Joyce WG, Rollot Y. In Press. An alternative interpretation of Peltochelys duchastelii as a

1126 paracryptodire. Fossil Record.

1127 Joyce WG, Sterli J. 2012. Congruence, non-homology, and the phylogeny of basal turtles. Acta 1128 Zoologica 93:149-159.

1129 Joyce WG, Chapman S, Moody RTJ, Walker CA. 2011. The skull of the solemydid turtle 1130 Helochelydra nopscai from the Early Creatceous of the Isle of Wight (UK) and a review of 1131 Solemydidae. Special Papers in Palaeontology 86:75-97.

1132 Joyce WG, Sterli J, Chapman S. 2014. The skeletal morphology of the solemydid turtle 1133 Naomichelys speciosa from the Early Cretaceous of Texas. Journal of Paleontology $1134 \quad \mathbf{8 8 ( 6 ) : 1 2 5 7 - 1 2 8 7 . ~}$

1135 Joyce WG, Rabi M, Clark JM, Xu X. 2016. A toothed turtle from the Late Jurassic of China 1136 and the global biogeographic history of turtles. BMC Evolutionary Biology 16(236):1-29.

1137 Kluge AG, Farris JS. 1969. Quantitative phyletics and the evolution of anurans. Systematic 1138 Biology 18:1-32. 
1139 Lipka TR, Therrien F, Weishampel DB, Jamniczky HA, Joyce WG, Colbert MW,

1140 Brinkman DB. 2006. A new turtle from the Arundel Clay Facies (Potomac Formation, Early

1141 Cretaceous) of Maryland, U.S.A. Journal of Vertebrate Paleontology 26(2):300-307.

1142 Lyson TR, Joyce WG. 2011. Cranial anatomy and phylogenetic placement of the enigmatic

1143 turtle Compsemys victa Leidy, 1856. Journal of Paleontology 85(4):749-801.

1144 Milner AR. 2004. The turtles of the Purbeck Limestone Group of Dorset, Southern England.

1145 Palaeontology 47(6): 1411-1467.

1146 Nixon KC, Carpenter JM. 1993. On outgroups. Cladistics 9:413-426

1147 Owen R. 1842. Report on British fossil reptiles. Part II. In: Report of the Eleventh Meeting of the

1148 British Association for the Advancement of Science; Held at Plymouth in July 1841. London:

1149 Murray, 60-204.

1150 Pérez-García A. 2014. Revision of the poorly known Dorsetochelys typocardium, a relatively

1151 abundant pleurosternid turtle (Paracryptodira) in the Early Cretaceous of Europe. Cretaceous

1152 Research 49:152-162.

1153 Pérez-García A, Royo-Torres R, Cobos A. 2015. A new European Late Jurassic pleurosternid

1154 (Testudines, Paracryptodira) and a new hypothesis of paracryptodiran phylogeny. Journal of

1155 Systematic Palaeontology 13(4):351-369.

1156 Rabi M, Zhou C-F, Wings O, Ge S, Joyce WG. 2013. A new xinjiangchelyid turtle from the

1157 Middle Jurassic of Xinjiang, China and the evolution of the basipterygoid process in

1158 Mesozoic turtles. BMC Evolutionary Biology 13(203):1-28.

1159 Rabi M, Sukhanov VB, Egorova VN, Danilov I, Joyce WG. 2014. Osteology, relationships, 1160 and ecology of Annemys (Testudines, Eucryptodira) from the Late Jurassic of Shar Teg, 
1161 Mongolia, and phylogenetic definitions for Xinjiangchelyidae, Sinemydidae, and

1162 Macrobaenidae. Journal of Vertebrate Paleontology 34(2):327-352.

1163 Rieppel O. 1980. The skull of the Upper Jurassic Cryptodire turtle Thalassemys, with a

1164 reconsideration of the chelonian braincase. Palaeontographica, Abteilung A 171:105-140.

1165 Rollot Y, Lyson TR, Joyce WG. 2018. A description of the skull of Eubaena cephalica (Hay,

1166 1904) and new insights into the cranial circulation and innervation of baenid turtles. Journal

1167 of Vertebrate Paleontology 38(3): 1474886

1168 Sterli J. 2010. Phylogenetic relationships among extinct and extant turtles: the position of

1169 Pleurodira and the effects of fossils on rooting crown-group turtles. Contributions to Zoology

$1170 \quad$ 79(3):93-106.

1171 Sterli J, Müller J, Anquetin J, Hilger A. 2010. The parabasisphenoid complex in Mesozoic

1172 turtles and the evolution of the testudinate basicranium. Canadian Journal of Earth Sciences

$1173 \quad 47: 1337-1346$.

1174 Sterli J, Pol D, Laurin M. 2013. Incorporating phylgenetic uncertainty on phylogeny-based

1175 palaeontological dating and the timing of turtle diversification. Cladistics 29:233-246.

1176 Sukhanov VB. 2000. Mesozoic turtles of middle and central Asia. In: Benton MJ, Shiskin MA,

1177 Unwin DM, Kurochkin EN, eds. The Age of Dinosaurs in Russia and Mongolia. Cambridge:

1178 Cambridge University Press, 309-367.

1179 Zhou C-F, Rabi M. 2015. A sinemydids turtle from the Jehol Biota provides insights into the 1180 basal divergence of crown turtles. Scientific Reports 5:16299. 
1182 Figure 1 Photographs of UMZC T1041, cranium of Pleurosternon bullockii. A, dorsal view.

1183 B, ventral view. C, left lateral view. D, right lateral view. E, anterior view. F, posterior view.

1184 Scale bar equals $10 \mathrm{~mm}$.

1185

1186 Figure 2 Three dimensional renderings of the cranium of Pleurosternon bullockii (UMZC

1187 T1041). A, dorsal view. B, ventral view. C, left lateral view. D, right lateral view. E, anterior

1188 view. F, posterior view. Abbreviations: bsp, parabasisphenoid; ep, epipterygoid; f, frontal; j,

1189 jugal; mx, maxilla; n, nasal; op, opisthotic; pa, parietal; pmx, premaxilla; po, postorbital; pr,

1190 prootic; prf, prefrontal; pt, pterygoid; q, quadrate; qj, quadratojugal; soc, supraoccipital; sq,

1191 squamosal. Scale bars equal $10 \mathrm{~mm}$.

1192

1193 Figure 3 Three dimensional renderings of the orbitotemporal region of Pleurosternon

1194 bullockii (UMZC T1041). A, anteroventral view of partial cranium. B, ventral view of partial

1195 cranium. Abbreviations: crcr, crista cranii; f, frontal; ftp, fossa temporalis; j, jugal; for, fossa

1196 orbitalis; pa, parietal; pip, processus inferior parietalis (descending process of parietal); po,

1197 postorbital; sol, sulcus olfactorius; sot, septum orbitotemporale; spp, sulcus palatino-

1198 pterygoideus. Scale bar equals $10 \mathrm{~mm}$.

1199

1200

Figure 4 Three dimensional renderings of the trigeminal region of Pleurosternon bullockii

1201 (UMZC T1041). A, anterodorsolateral view of partial right cranium. B, anterolateral view of

1202 partial right cranium. Abbreviations: ep, epipterygoid; fnt, foramen nervi trigemini (trigeminal

1203 foramen); fst, foramen stapedio-temporale; pa, parietal; pepi, processus epipterygoideus; pip,

1204 processus inferior parietalis (descending process of parietal); pppa, posterior process of parietal 
1205 behind trigeminal foramen; pr, prootic; pt, pterygoid; pto-pr, prootic part of processus trochlearis

1206 oticum; pto-q, quadrate part of processus trochlearis oticum; q, quadrate; soc, supraoccipital.

1207 Scale bar equals $10 \mathrm{~mm}$.

1208

1209 Figure 5 Three dimensional renderings of aspects of the cavum acustico-jugulare and the

1210 inner ear capsule of Pleurosternon bullockii (UMZC T1041). A, posteroventral view of partial

1211 right basicranium. B, posterolateral view of right prootic and pterygoid. C, lateral view of left

1212 prootic and opisthotic. D, medial view of left prootic and opisthotic. Abbreviations: acst, aditus

1213 canalis stapedio-temporalis; asc, anterior semicircular canal; bs-f, parabasisphenoid-facet; ccav,

1214 canalis cavernosus; ex-f, exoccipital facet; faf, fossa acustico-facialis; fja, foramen jugulare

1215 anterius; fnac, foramen nervi acustici; fov, fenestra ovalis; hac, hiatus acusticus; ica, incisura

1216 columella auris; lfng, lateral foramen nervi glossopharyngei; lsc, lateral semicircular canal;

$1217 \mathrm{mfng}$, medial foramen nervi glossopharyngei; mfnf, medial foramen nervi facialis; op, opisthotic;

1218 pif, processus interfenestralis; plf, perilymphatic fossa; ppo, paroccipital process; pr, prootic; pr-

1219 1sc, prootic-part of the lateral semicircular canal; psc, posterior semicircular canal; pt, pterygoid;

1220 q, quadrate; snhy, sulcus nervi hyomandibularis; soc, supraoccipital. Scale bars equals $10 \mathrm{~mm}$ in

1221 A, $3 \mathrm{~mm}$ in B-D.

1222

1223 Figure 6 Three dimensional renderings of the right pterygoid of Pleurosternon bullockii

1224 (UMZC T1041). A, ventral view. B, dorsal view. C, anterodorsolateral view. Abbreviations:

1225 afnv, anterior foramen for the canalis nervus vidiani; bpp-f, basisptergyoid process facet; bsp-f,

1226 parabasisphenoid facet; ccav; canalis cavernosus; crpt, crista pterygoidei; ep-f, epipterygoid

1227 facet; j-f, jugal facet; mx-f, maxilla facet; pfnv, posterior foramen for the canalis nervus vidiani; 
1228 ppe, processus pterygoideus externus; pptp, posterior pterygoid process; pr-f, prootic facet; ptf, 1229 pterygoid fossa; q-f, quadrate facet; scav, sulcus cavernosus; vf, vertical flange of the external 1230 pterygoid process; vptr, ventral pterygoid ridge. Scale bar equals $3 \mathrm{~mm}$.

1231

1232 Figure 7 Three dimensional renderings of the parabasisphenoid and basipterygoid process

1233 of Pleurosternon bullockii (UMZC T1041). A, parabasisphenoid in dorsal view. B, 1234 parabasisphenoid in ventral view. C, parabasisphenoid and left pterygoid in ventral view. D, 1235 parabasisphenoid in anterodorsal view. E, parabasisphenoid in left lateral and slight ventral view. 1236 Abbreviations: atbs, anterior tubercula basisphenoidale; bpp-df, dorsal flange of basipterygoid 1237 process; bpp-vf, ventral flange of basipterygoid process; cag, carotid groove; clp, clinoid 1238 process; cprnv, canalis pro ramo nervi vidiani; ctb, crista tuberculi basalis; ds, dorsum sellae; 1239 faccc, foramen anterius canalis carotici cerebralis; fna, foramen nervi abducentis; fpccc, foramen 1240 posterius canalis carotici cerebralis; pt-f, pterygoid facet; ptf, pterygoid fossa; rbp, retractor bulbi 1241 pit; rbs, rostrum basisphenoidale; st, sella turcica; vptr, ventral pterygoid ridge. Scale bar equals $12423 \mathrm{~mm}$. 
Figure 1

Photographs of UMZC T1041, cranium of Pleurosternon bullockii.

A, dorsal view. B, ventral view. C, left lateral view. D, right lateral view. E, anterior view. F, posterior view. Scale bar equals $10 \mathrm{~mm}$.

A

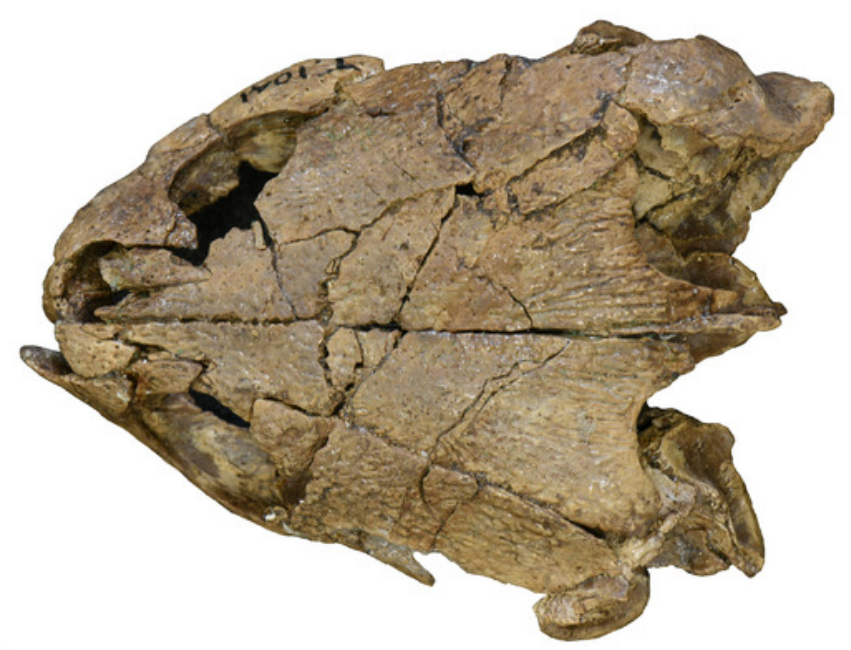

C

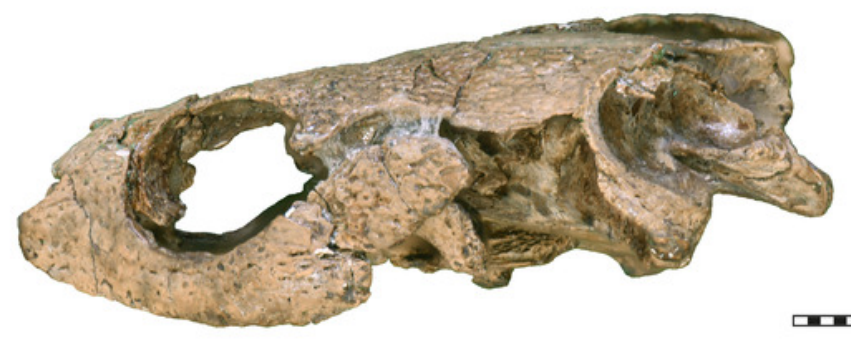

E

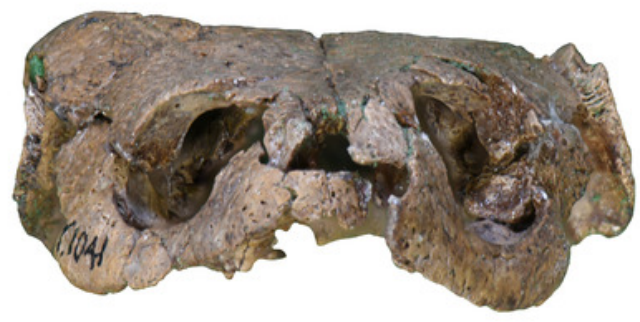

B

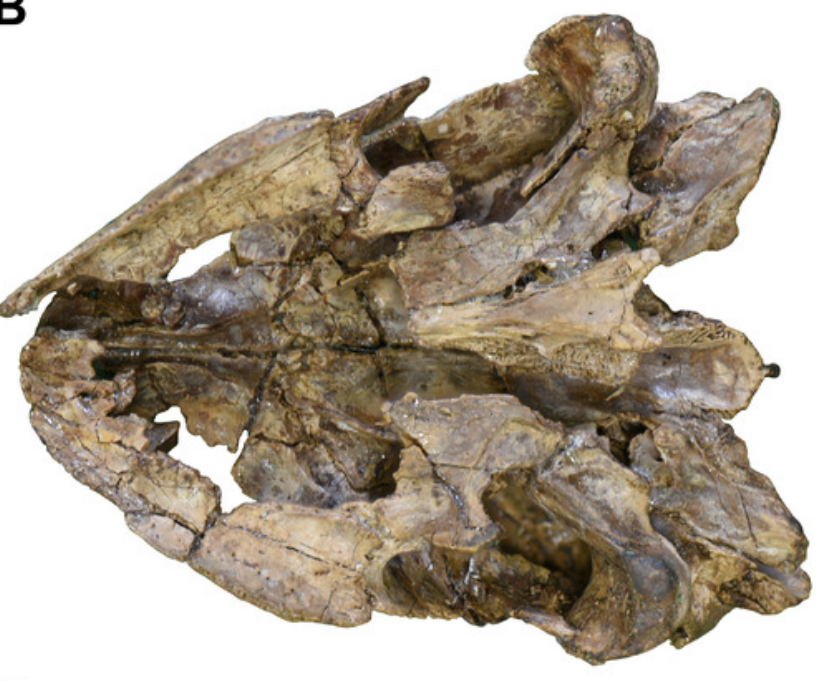

D

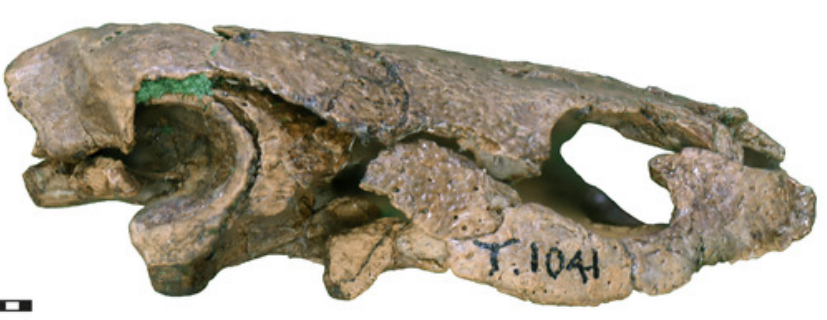

$\mathbf{F}$

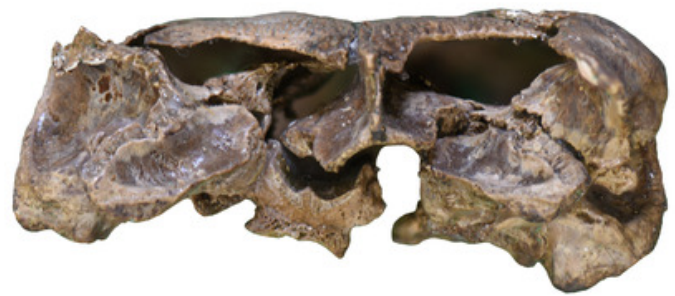




\section{Figure 2}

Three dimensional renderings of the cranium of Pleurosternon bullockii (UMZC T1041).

A, dorsal view. B, ventral view. C, left lateral view. D, right lateral view. $E$, anterior view. F, posterior view. Abbreviations: bsp, parabasisphenoid; ep, epipterygoid; f, frontal; j, jugal; mx, maxilla; n, nasal; op, opisthotic; pa, parietal; pmx, premaxilla; po, postorbital; pr, prootic; prf, prefrontal; pt, pterygoid; q, quadrate; qj, quadratojugal; soc, supraoccipital; sq, squamosal. Scale bars equal $10 \mathrm{~mm}$. 


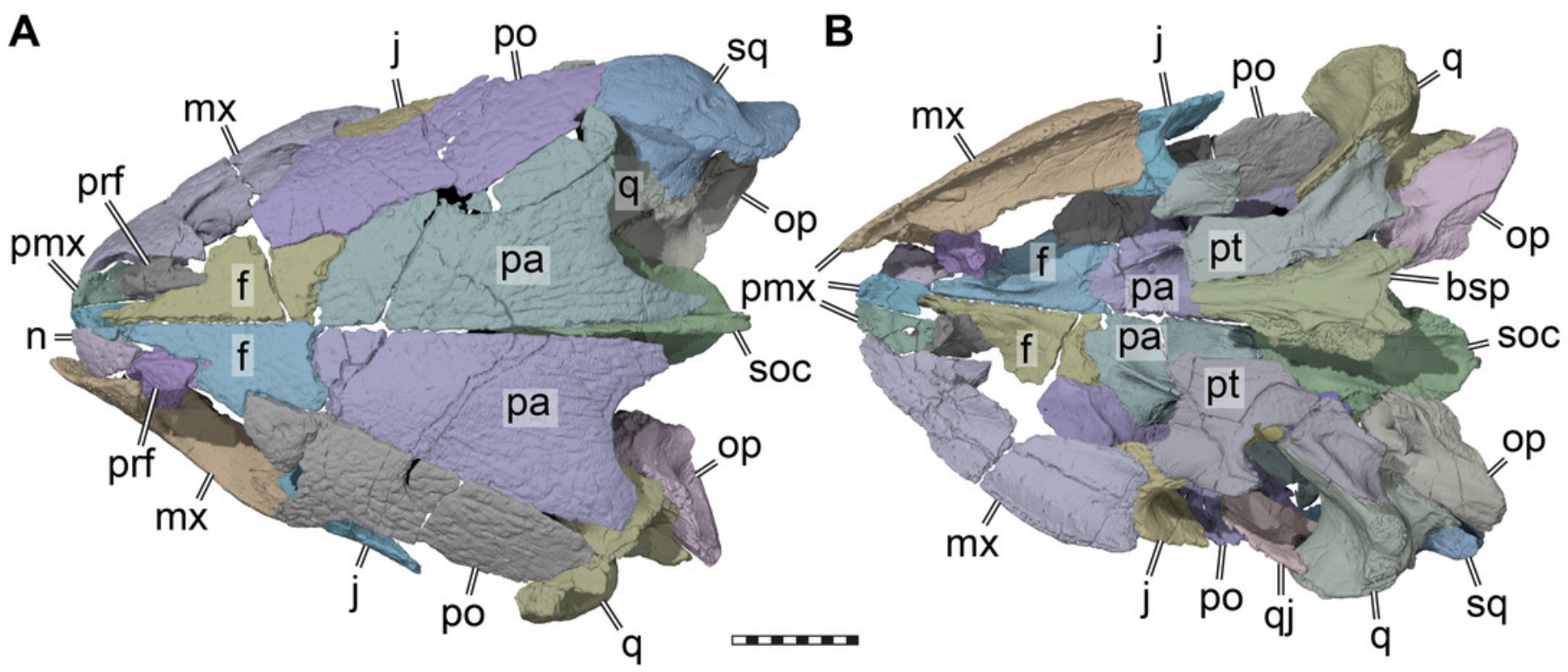

C

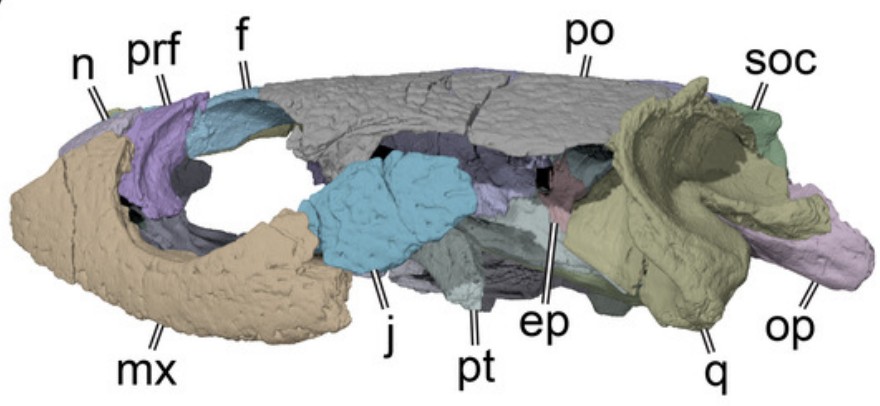

E

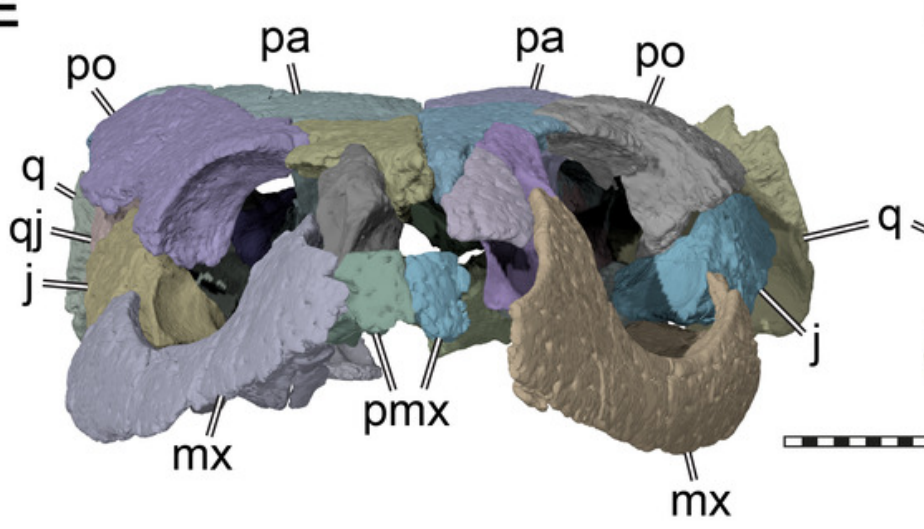

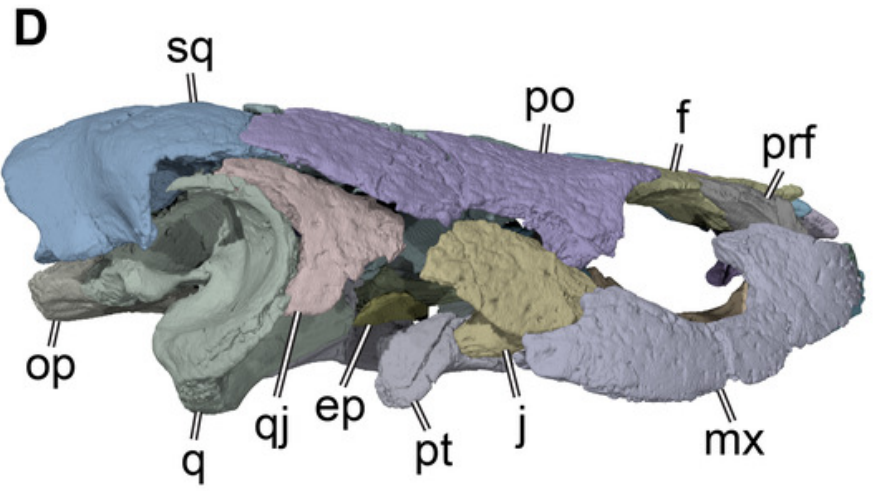

F

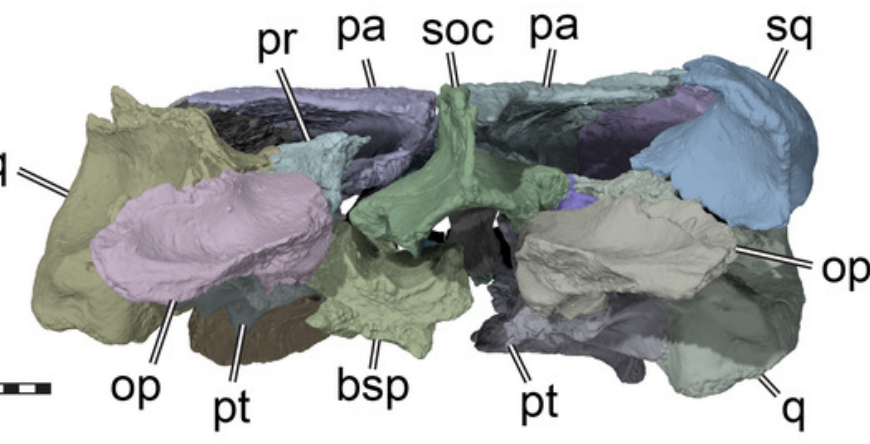




\section{Figure 3}

Three dimensional renderings of the orbitotemporal region of Pleurosternon bullockii (UMZC T1041).

A, anteroventral view of partial cranium. B, ventral view of partial cranium. Abbreviations: crcr, crista cranii; f, frontal; ftp, fossa temporalis; j, jugal; for, fossa orbitalis; pa, parietal; pip, processus inferior parietalis (descending process of parietal); po, postorbital; sol, sulcus olfactorius; sot, septum orbitotemporale; spp, sulcus palatino-pterygoideus. Scale bar equals $10 \mathrm{~mm}$.

A

B

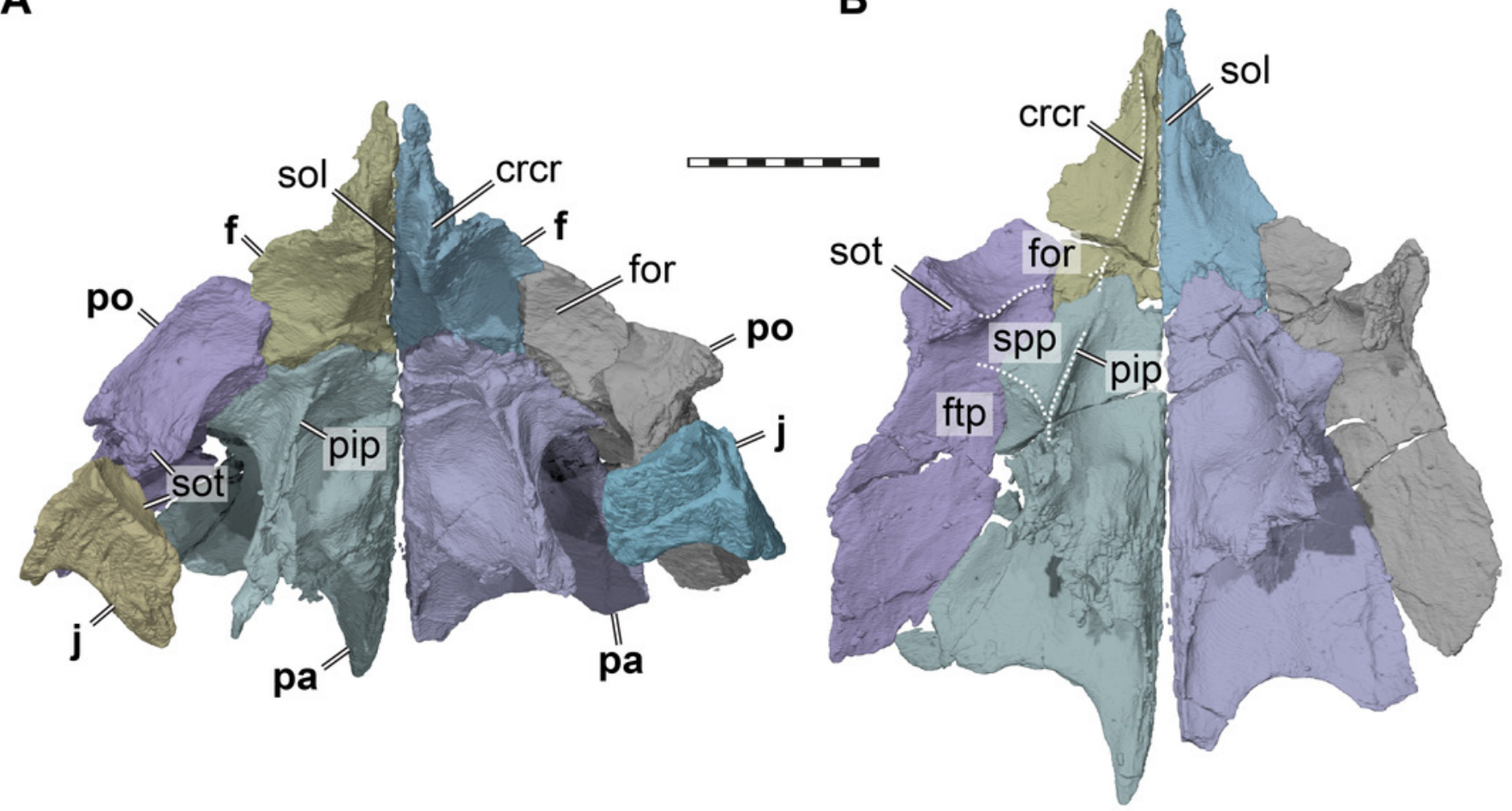




\section{Figure 4}

Three dimensional renderings of the trigeminal region of Pleurosternon bullockii (UMZC T1041).

A, anterodorsolateral view of partial right cranium. B, anterolateral view of partial right cranium. Abbreviations: ep, epipterygoid; fnt, foramen nervi trigemini (trigeminal foramen); fst, foramen stapedio-temporale; pa, parietal; pepi, processus epipterygoideus; pip, processus inferior parietalis (descending process of parietal); pppa, posterior process of parietal behind trigeminal foramen; pr, prootic; pt, pterygoid; pto-pr, prootic part of processus trochlearis oticum; pto-q, quadrate part of processus trochlearis oticum; q, quadrate; soc, supraoccipital. Scale bar equals $10 \mathrm{~mm}$.

A

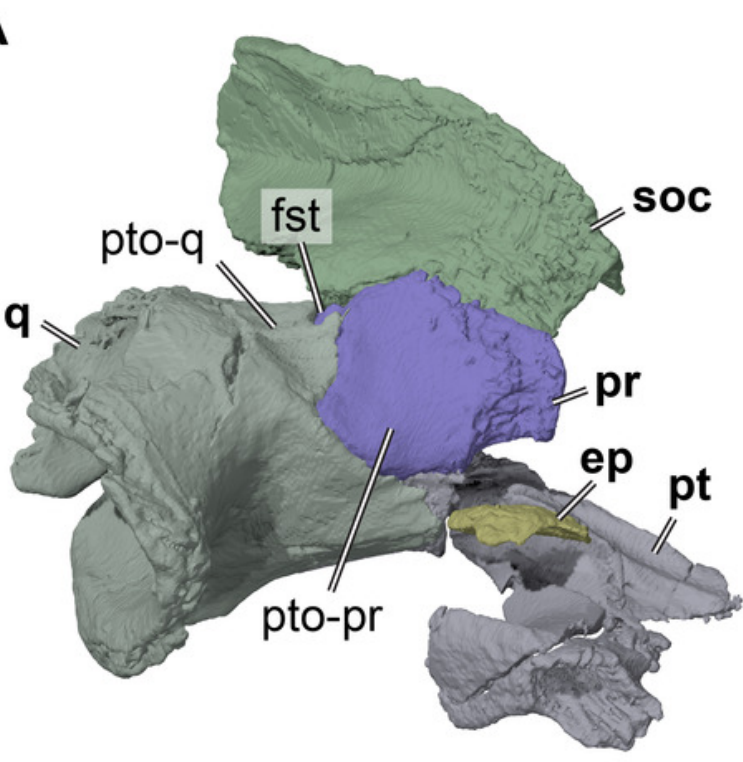

B

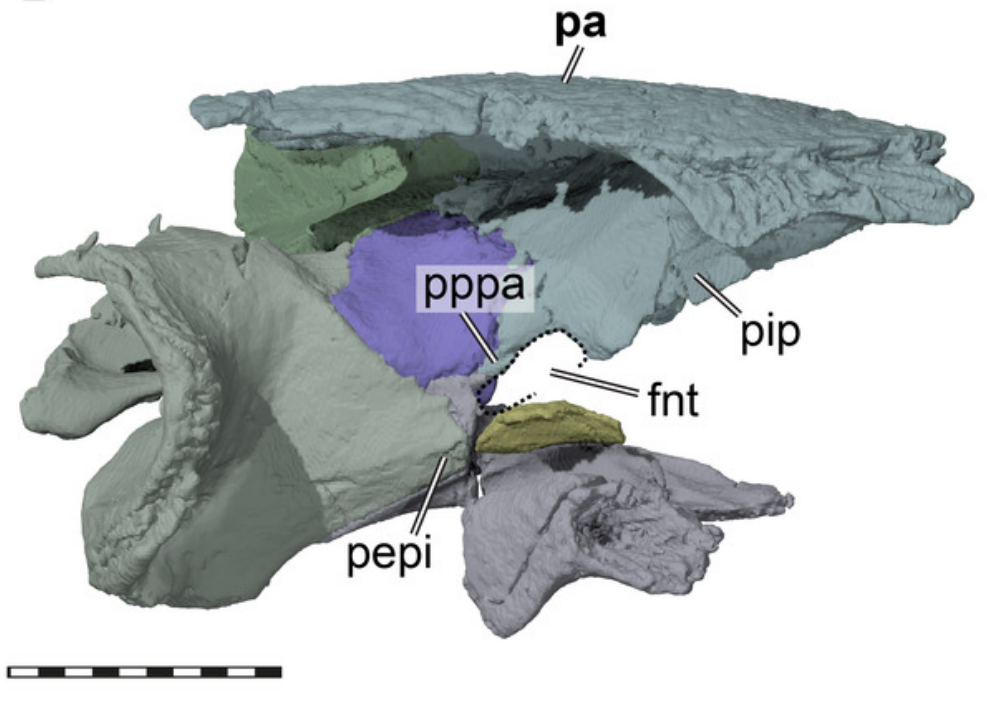




\section{Figure 5}

Three dimensional renderings of aspects of the cavum acustico-jugulare and the inner ear capsule of Pleurosternon bullockii (UMZC T1041).

A, posteroventral view of partial right basicranium. B, posterolateral view of right prootic and pterygoid. C, lateral view of left prootic and opisthotic. D, medial view of left prootic and opisthotic. Abbreviations: acst, aditus canalis stapedio-temporalis; asc, anterior semicircular canal; bs-f, parabasisphenoid-facet; ccav, canalis cavernosus; ex-f, exoccipital facet; faf, fossa acustico-facialis; fja, foramen jugulare anterius; fnac, foramen nervi acustici; fov, fenestra ovalis; hac, hiatus acusticus; ica, incisura columella auris; Ifng, lateral foramen nervi glossopharyngei; Isc, lateral semicircular canal; mfng, medial foramen nervi glossopharyngei; mfnf, medial foramen nervi facialis; op, opisthotic; pif, processus interfenestralis; plf, perilymphatic fossa; ppo, paroccipital process; pr, prootic; pr-Isc, prootic-part of the lateral semicircular canal; psc, posterior semicircular canal; pt, pterygoid; q, quadrate; snhy, sulcus nervi hyomandibularis; soc, supraoccipital. Scale bars equals $10 \mathrm{~mm}$ in A, $3 \mathrm{~mm}$ in B-D. 
A

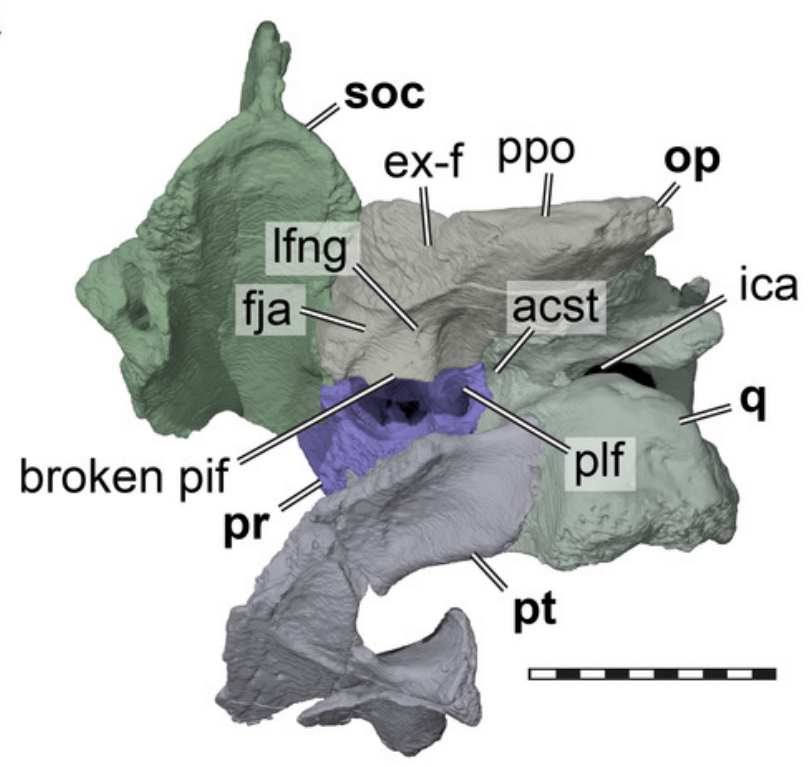

B

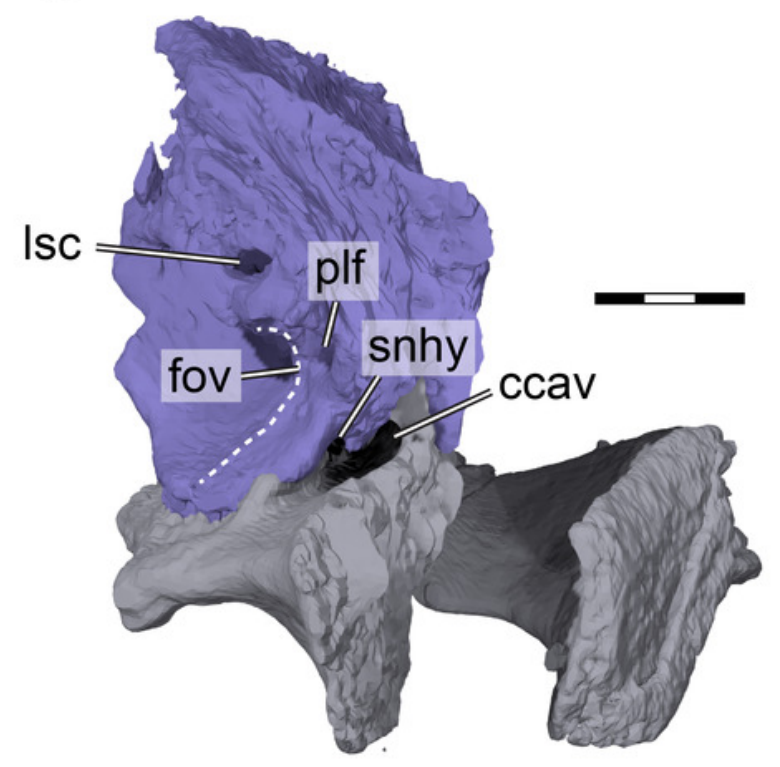

C

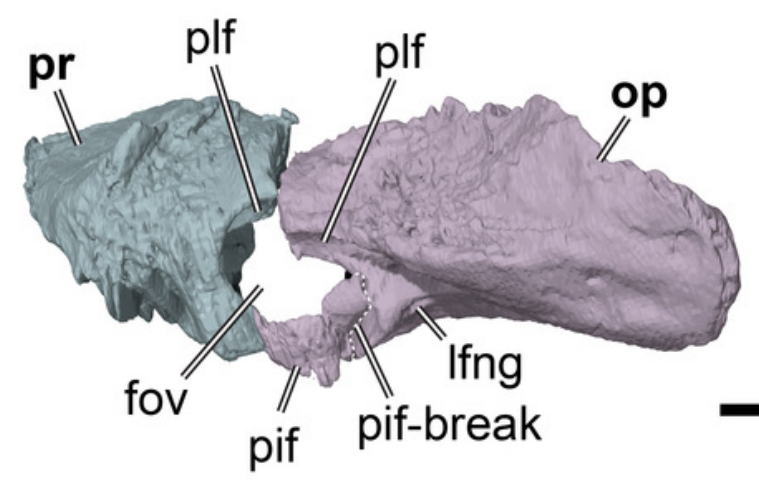

D

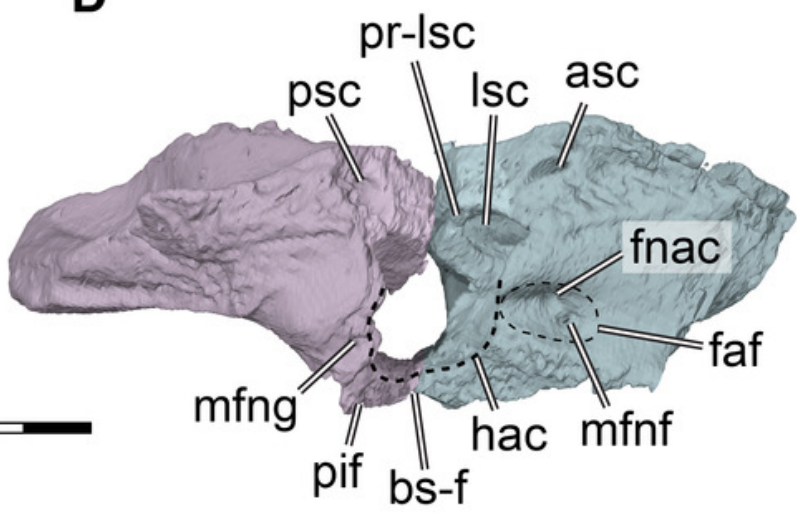




\section{Figure 6}

Three dimensional renderings of the right pterygoid of Pleurosternon bullockii (UMZC T1041).

A, ventral view. B, dorsal view. C, anterodorsolateral view. Abbreviations: afnv, anterior foramen for the canalis nervus vidiani; bpp-f, basisptergyoid process facet; bsp-f, parabasisphenoid facet; ccav; canalis cavernosus; crpt, crista pterygoidei; ep-f, epipterygoid facet; j-f, jugal facet; mx-f, maxilla facet; pfnv, posterior foramen for the canalis nervus vidiani; ppe, processus pterygoideus externus; pptp, posterior pterygoid process; pr-f, prootic facet; ptf, pterygoid fossa; q-f, quadrate facet; scav, sulcus cavernosus; vf, vertical flange of the external pterygoid process; vptr, ventral pterygoid ridge. Scale bar equals $3 \mathrm{~mm}$.

A

B

C
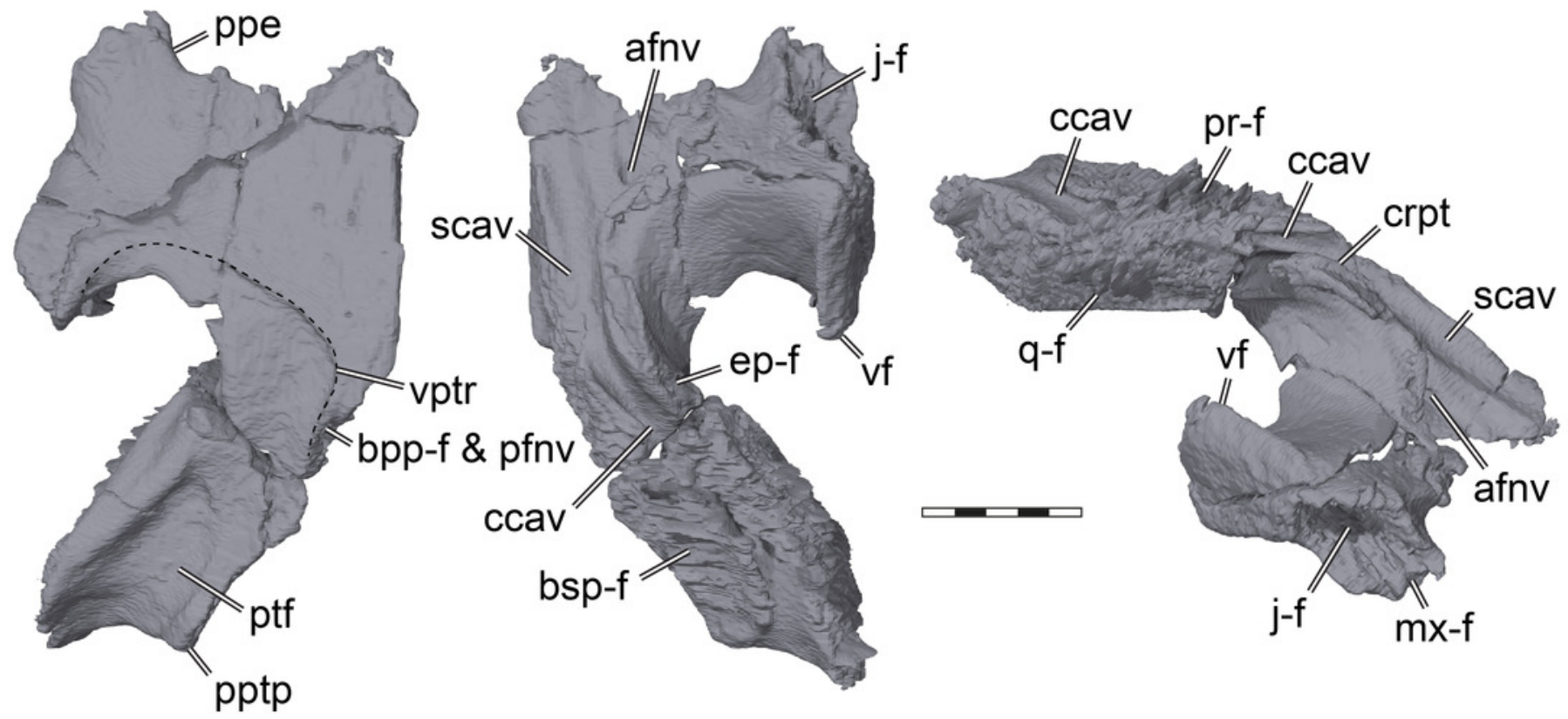


\section{Figure 7}

Three dimensional renderings of the parabasisphenoid and basipterygoid process of Pleurosternon bullockii (UMZC T1041).

A, parabasisphenoid in dorsal view. B, parabasisphenoid in ventral view. C, parabasisphenoid and left pterygoid in ventral view. D, parabasisphenoid in anterodorsal view. E, parabasisphenoid in left lateral and slight ventral view. Abbreviations: atbs, anterior tubercula basisphenoidale; bpp-df, dorsal flange of basipterygoid process; bpp-vf, ventral flange of basipterygoid process; cag, carotid groove; clp, clinoid process; ctb, crista tuberculi basalis; ds, dorsum sellae; faccc, foramen anterius canalis caroticus cerebralis; fna, foramen nervi abducentis; fpccc, foramen posterius canalis caroticus cerebralis; fprnv, foramen pro ramo nervi vidiani; pt-f, pterygoid facet; ptf, pterygoid fossa; rbp, retractor bulbi pit; rbs, rostrum basisphenoidale; st, sella turcica; vptr, ventral pterygoid ridge. Scale bar equals 3 $\mathrm{mm}$. 
A

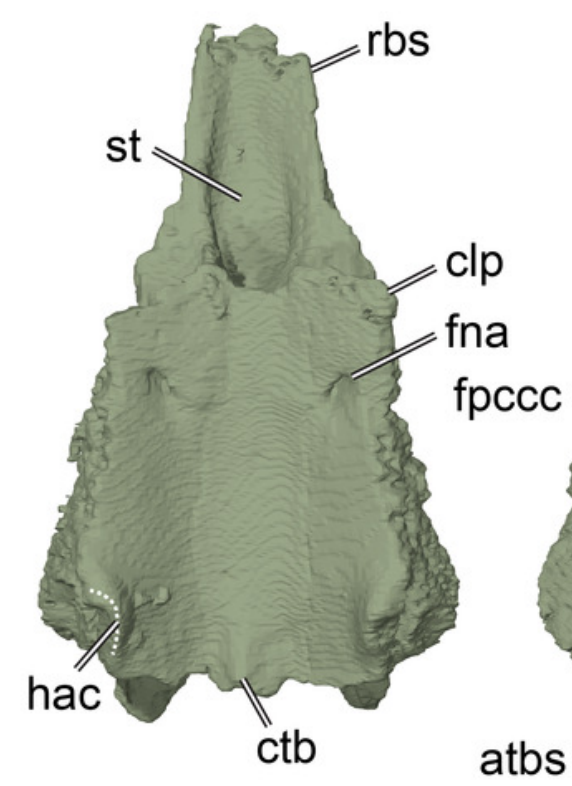

D

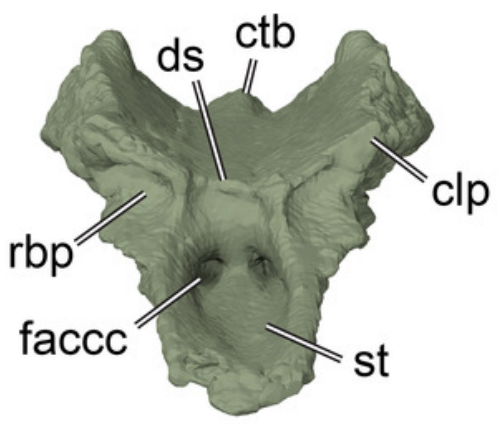

B

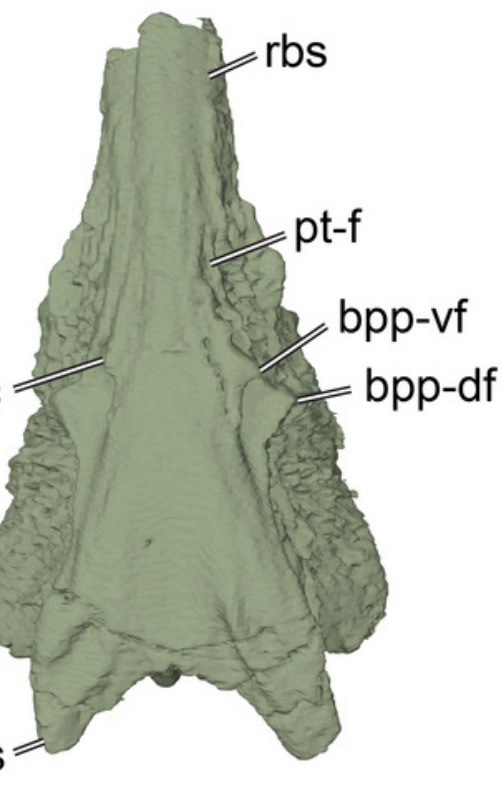

C

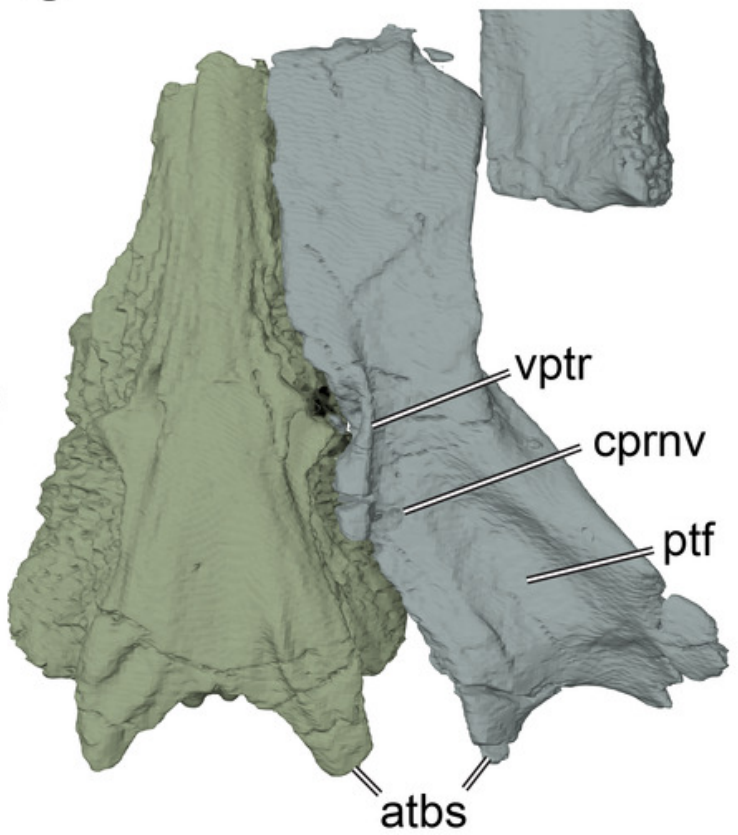

E
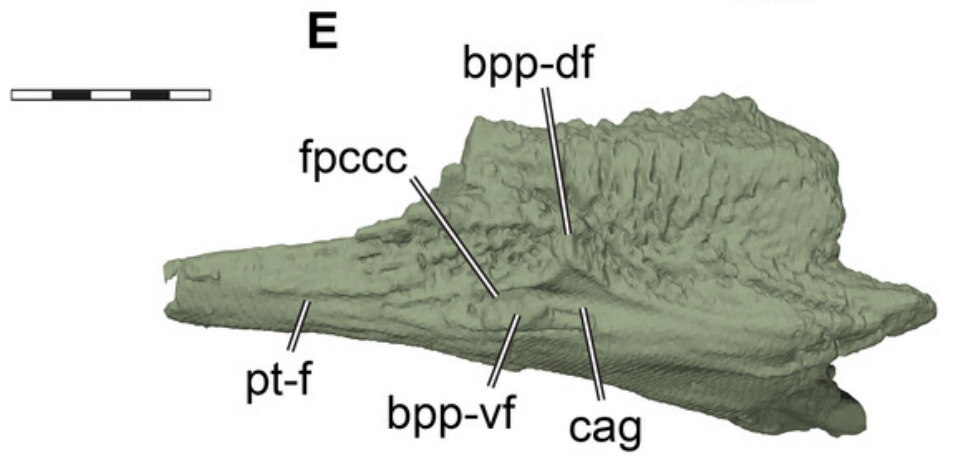